\title{
"LA EXPOSICIÓN DE LOS COSTOS OCULTOS DE LA TRIBUTACIÓN EN EL SISTEMA DE PRESUPUESTO Y CONTABILIDAD PÚBLICA"*
}

SERGIO MIGUEL HAUQUE

FACULTAD DE CIENCIAS ECONÓMICAS UNIVERSIDAD NACIONAL DEL LITORAL

"El presupuesto nacional debe ser equilibrado. Las deudas públicas deben ser reducidas. La arrogancia de las autoridades debe ser moderada y controlada. Los pagos a gobiernos extranjeros deben ser reducidos si la nación no quiere ir a la quiebra. Las personas deben nuevamente aprender a trabajar, en vez de vivir por cuenta pública." 
"Toda contribución debe percibirse de tal forma que haya la menor diferencia posible entre las sumas que salen del bolsillo del contribuyente y las que se ingresan en el Tesoro público...De uno u otro de estos...modos distintos, los impuestos llegan a ser mucho más gravosos para el pueblo que ventajosos para el Soberano" (Smith, 1958: 727/728).

Para arrancar cantidades siempre crecientes a un organismo mal predispuesto se ha creado un enorme aparato administrativo que no hace más que luchar contra la burguesía por cada dólar que le cobra. Como réplica ese organismo ha desarrollado órganos de defensa que realizan una enorme cantidad de trabajo de autoprotección. En una sociedad socialista no existiría(n) tales despilfarros...Como dominaría todas las fuentes de renta, los impuestos podrían desaparecer...(por lo que) la supresión de los impuestos constituye uno de los títulos de superioridad más significativos que se pueden reconocer al plan socialista" (Schumpeter, 1996: Tomo I: 260/1).

\section{RESUMEN}

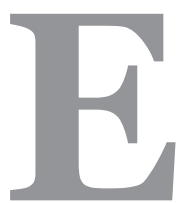

l principal objeto de este trabajo es aproximarnos a la lista completa y la clasificación de los costos sociales de un sistema tributario. Propone además exponerlos lo más explícitamente posible en el sistema presupuestario y contable del Sector Público armonizado, en el marco del actual proceso de transición desde una información puramente financiera, hacia un sistema de información integrado para la toma de decisiones.

Sostenemos a lo largo de este trabajo, que el sistema presupuestario y contable del Sector Público debería poder separar los siguientes conceptos que actualmente se encuentran "enmascarados" dentro del neto recaudado, permitiendo así determinar correctamente el flujo completo de recursos tributarios a través de la cuantificación de los:

Costos "internos" del Sector Público

- Los costos por "gastos tributarios"

- Los costos representados por la evasión tributaria

- Los costos de la incobrabilidad efectiva de los tributos y sus accesorios y los Costos "externos" al Sector Público

- Los costos sociales de los contribuyentes

- Los costos sociales de eficiencia de la imposición de tributos distorsivos.

$\mathrm{Al}$ mismo tiempo, se concluye que el sistema presupuestario y contable del Sector Público debe reconocer los efectos sobre los flujos y stocks relativos al sistema tributarios que producen los cambios en el nivel general de precios absolutos del sistema económico.

Palabras claves: Tributos - Cuentas Públicas - Devengado - Costos sociales - Costos ocultos. 


\begin{abstract}
The aim of the paper is to propose a complete list together with a taxonomy of the social costs of a taxation system. It also includes proposals for an explicit exposition of these costs in the public budget and accounting system, as another step in the transition process from simple financial information systems into integrated systems for decision-making in the Public Sector.

We argue for the possibility of unhiding the bulk of the social costs of the taxation system through an adequate budgeting and accounting process. These costs items are:

"Internal" Public Sector costs

- Tax expenditures

- Tax evasion.

- Not collected determined taxes

and "External" Public Sector costs

- Tax-payers social costs.

- Efficiency costs caused by distortionary taxes.

At the same time, these systems must recognize the effects on the flows and stocks of the taxation system, produced by changes in absolute price levels of the whole economic system.
\end{abstract}

Keywords: Taxes - Public accounts - Accrual basis - Social costs - Hidden costs.

\title{
INTRODUCCIÒN
}

Los epígrafes nos recuerdan que grandes autores de la Economía han resaltado desde siempre el importante rol de los costos sociales de la tributación dentro del sistema económico. Smith, en 1776, aceptando el "mal necesario" de los tributos, pero exigiendo la minimización de los costos que el sistema tributario determina. Schumpeter, en 1942, incluyendo entre las principales desventajas del capitalismo el "despilfarro" que implica un sistema impositivo moderno, dado que la permanente confrontación entre Sector Público y Sector Privado para definir el monto efectivo que el segundo debe transferir al primero, implica de por sí un ingente sacrificio de recursos sociales, que podrían tener usos alternativos mucho más útiles en un sistema socialista sin tributos.

Más allá de la opinión del lector sobre las bondades y/o los defectos de los sistemas capitalista y socialista, no será difícil coincidir en que el sistema tributario de una Nación, implica fuertes costos de toda índole ${ }^{1}$. El principal objeto de este trabajo es intentar aproximarnos a la realización de una lista completa y una clasificación de los costos sociales totales de un sistema tributario, teniendo especialmente en cuenta que algunos de ellos son subvaluados o directamente olvidados al momento de decidir sobre la imposición de un nuevo tributo. Al mismo tiempo, realizaremos propuestas para mostrarlos lo más explícitamente posible dentro el sistema presupuestario y contable del Sector Público, en el marco del actual proceso de

${ }^{1}$ Son obras señeras en este campo especialmente las de Robert Haig en 1935 y de Cedric Sanford en 1973. (cfr. Evans, 2001) 
transición desde una información esencialmente financiera, hacia un sistema de información pública integrado para la toma de decisiones.

Este análisis se realizará tratando de observar al fenómeno de la tributación desde las distintas disciplinas que se ocupan del mismo, como la Economía del Sector Público, la Administración Tributaria, el Derecho Tributario y la Contabilidad Pública. En este sentido, estamos convencidos que limitarnos a un enfoque reduccionista desde un único punto de vista sería caer en el máximo de los absurdos ${ }^{2}$.

Creemos además que la herramienta del Presupuesto Público debe ser explotada al máximo como una de las vías ideales para que la sociedad pueda conocer, aprobar y/o rechazar la existencia y cuantía de estos costos. Existe una tendencia muchas veces observada en los profesionales del Sector Público a constreñirse a una profunda exégesis de "lege lata" de las normas vigentes para su aplicación a los casos particulares de estados nacionales y subnacionales, sintiéndose muchas veces limitados en la realización de propuestas no incluidas expresamente dentro del marco legal vigente. De ningún modo desdeñamos dicha vertiente de labor profesional, pero creemos necesario internarnos también en la discusión doctrinaria de "lege ferenda" de los componentes y formas de determinación del presupuesto y la contabilidad pública desde una perspectiva más amplia. Estamos convencidos que así podremos abrir caminos nuevos y más fecundos para las investigaciones dirigidas a mejorar los mecanismos de información del accionar del Sector Público en los Estados modernos.

La idea subyacente a lo largo de todo este trabajo es que los sistemas de información presupuestaria y contable integrados de un Sector Público moderno, no sólo deben cumplir con las normas vigentes y permitir el control financiero de sus acciones; sino también resultar insumos básicos para la toma de decisiones del propio Sector Público y de la sociedad, a la vez de integrarse a la información macrocontable del sistema económico nacional.

\section{A) ¿QUÉ FLUJOS Y STOCKS DEBEN SER REGISTRADOS POR LOS SISTEMAS DE INFORMACIÓN DEL SECTOR PÚBLICO?}

\section{1) Breve presentaciòn del problema}

El registro de flujos y stocks económicos, financieros y patrimoniales en el Sector Público, especialmente en el campo de la información contable ex post, está sufriendo en los últimos años un proceso de reanálisis y adecuación. Ciertos criterios generalizadamente aceptados desde hace siglos por la Microcontabilidad privada, como la utilización del sistema de partida doble y el registro de los flujos en el momento del devengamiento, han sido redescubiertos por la Microcontabilidad pública y aplicados a los diversos casos de entes del Sector Público ${ }^{3}$.

\footnotetext{
2 "To undertake or to refrain from undertaking any interesting task out of respect for frontiers or tectonics would be the height of absurdity" (Iniciar o no iniciar una tarea interesante por respeto a las fronteras disciplinares sería el máximo de los absurdos) (Schumpeter, 1968: 23 - La traducción es propia)

${ }^{3}$ Nuestra visión sigue la tendencia unificadora de la obra de Mattessich que define así a la Contabilidad en 1963: “Un enfoque aceptado para construir una definición sólida consiste en partir del punto de vista generalmente aceptado acerca del contenido del asunto.... El adherir a este procedimiento, implicaría en nuestra disciplina dejar de lado todos los sistemas macrocontables. En la práctica, y en grado considerable en la teoría, el término 'Contabilidad' se emplea para designar solamente a la Microcon-
} 
En la actualidad, el Sector Público se encuentra ante los problemas que implica la modificación de los criterios tradicionales para la determinación del momento del reconocimiento presupuestario y contable de los flujos de recursos tributarios, especialmente en cuanto afectan al resultado patrimonial de un ente público. En efecto, el tradicional método de reconocerlos al momento del cobro, cede lugar a la necesidad de su reconocimiento en el momento en que los mismos fueron efectivamente devengados.

Creemos que estas tendencias deben también ser tenidas en cuenta en el proceso presupuestario, en la búsqueda de una integración de los distintos sistemas de información, refieran éstos a datos proyectados o históricos. Es así que el criterio de lo devengado, que ha enriquecido la información contable sobre hechos pasados de los entes públicos que lo han adoptado, también permitirá completar la información sobre hechos proyectados que se incluyen en sus sistemas presupuestarios. No parece razonable limitarnos exclusivamente a presupuestos de flujos y stocks puramente financieros para brindar información sobre la actuación del principal actor económico de la mayoría de los sistemas modernos, sino que los mismos deberían completarse con información presupuestada sobre aspectos económicos y patrimoniales.

En resumen: "Un buen sistema de información...tiene necesidad...(de) integrar simultánea y automáticamente ambos instrumentos: presupuesto y contabilidad con la mayor economía de esfuerzos en el proceso de compatibilización. En esencia éste es el requisito básico requerido para el diseño de una contabilidad gerencial gubernamental" (Las Heras, 2004: 309).

\section{2) La importancia de la llegada del devengado a la información contable del sector público}

En realidad, más allá de que el criterio de lo devengado ha sido utilizado desde hace varios siglos en la microcontabilidad privada, es necesario destacar que la irrupción de dicho criterio en las cuentas públicas resulta muy actual y se debe a la influencia de los "macrocontadores" que trabajan en las cuentas de los sistemas económicos nacionales. Puestos en la necesidad de compatibilizar las bases de atribución de flujos a períodos de las distintas fuentes utilizadas, optaron claramente por el "devengamiento" como mecanismo unificador. De esta manera, los contadores públicos fueron "forzados” a presentar informes sobre esa base, esencialmente para poder integrarse al sistema de cuentas nacionales.

Realizaremos a continuación un breve desarrollo de la historia reciente, que nos permite observar esta evolución:

tabilidad......los contadores, los hombres de negocios y muchos profesores de contabilidad -tal como lo demuestra la enseñanza impartida por los mismos- consideran los sistemas macrocontables como parientes lejanos de la Contabilidad, la cual por mero accidente tomó un nombre que resulta engañoso con respecto a los conceptos que esconde .......existen fuerzas que han reconocido la conveniencia de integrar a la micro y a la macrocontabilidad a nivel teórico. Nuestro punto de vista es más radical aún: no queremos expresar la conveniencia de tal integración, sino que planteamos su necesidad..." (Mattessich, 2002: 15-16. El destacado es propio). Del mismo modo consideramos necesaria la integración entre la información presupuestaria y la contable en todos estos campos, las que deben observar los mismos fenómenos desde un enfoque ex-ante y ex-post respectivamente, permitiendo así la detección y análisis de los posibles desvíos. 
a) El Sistema de Cuentas Nacionales de las Naciones Unidas

El Sistema de Cuentas Nacionales de Naciones Unidas tiene versiones desde 1953. La revisión 1968 del Sistema estuvo en uso hasta la entrada en vigencia del "System of National Accounts 1993" (SNA 1993). Esta última ${ }^{4}$ se pronunció definitivamente a favor del "full accrual accounting" o "método de acumulación", sin las excepciones aceptadas por el sistema de 1968. Este cambio generó una clara inconsistencia del SNA con los sistemas de cuentas nacionales ligados con el Sector Público, que compilaban sus cuentas sobre base caja. Los lineamientos del SNA 1993 fueron adoptados en general por la mayoría de los países del mundo, al mismo tiempo que los sistemas de cuentas nacionales custodiados por el Fondo Monetario Internacional relativos al Sector Público y al Sector Externo, iniciaban su transformación.

b) La versión 1993 del Balance of Payments Manual (BPM 5) del Fondo Monetario Internacionals:

Siguiendo este criterio, el manual de Balanza de Pagos del Fondo Monetario Internacional, publicado por primera vez en 1993, se adscribe totalmente al sistema de lo devengado, utilizándolo generalizadamente respecto de los modos de registración de pagos internacionales, aún en el caso de intereses.

c) La versión 2001 del Sistema de Estadísticas de Finanzas Públicas del Fondo Monetario Internacional:

La mayor resistencia al cambio para la armonización general de los sistemas se dio en el ámbito del Government Finance Statistics Manual (GFSM) compilado por el Fondo Monetario Internacional. La versión 1986 del GFSM seguía haciendo profesión de fe del sistema base caja, al que consideraba más adecuado para el registro de los flujos y stocks relacionados con el Sector Público. Los documentos de trabajo previos a la modificación del sistema resumieron los argumentos a favor y en contra, pronunciándose claramente a favor de lo devengado (cfr. entre otros Efford, 1996). Las reglas de registro del sistema se modificaron adoptando el sistema de lo devengado en la versión 2001.

d) El sistema de las Normas Internacionales de Contabilidad del Sector Público:

Desde el momento de la emisión de la primera norma internacional de contabilidad para el Sector Público en 2001, el International Public Sector Accounting Standard Board (IPSASB) se mostró a favor de la utilización del sistema de lo devengado, traducido al castellano como "método de acumulación".

\footnotetext{
${ }^{4}$ A raíz de un proceso de actualización iniciado en 2003, existe una versión del Sistema de Cuentas Nacionales 2008 disponible al momento de escribir este trabajo en idioma inglés. Dicho texto puede consultarse en http://unstats.un.org/unsd/nationalaccount/sna2008.asp. El punto 3 del System of National Accounts 2008 (SNA 2008) titulado "Time of Recording" ratifica expresamente la adopción del criterio de "accrual basis". Es destacable que el punto 1.70. del SNA 2008 refuerza la idea de coordinación de criterios entre todos los sistemas contables al considerar como un elemento central para su utilización, la difusión de las normas internacionales de información financiera emitidas por el International Accounting Standard Board (IASB) y el IPSASB.

${ }^{5}$ También se encuentra en proceso de difusión la propuesta de Balance of Payments Manual 6 que actualiza la quinta versión de 1993.
} 
La transición práctica no traumática de los sistemas de contabilidad gubernamental desde los registros sobre base caja hacia la base devengado resultó uno de los objetivos de la labor del IPSASB, lo que resultó en la producción del Estudio Nro 14 para guía de los organismos gubernamentales que decidieran poner manos a la obra en la tarea (cfr. International Federation of Accountants, 2002). Para el caso de los recursos públicos el International Public Sector Accounting Standard Nro. 23 de 2006 fijó reglas concretas para la utilización de este criterio en el caso de tributos y transferencias.

Sin embargo, el proceso de transformación del sistema de información del Sector Público resulta lento y difícil por los inconvenientes que implica esta transición, a pesar de los esfuerzos internacionales sobre el tema. La utilización del criterio de lo devengado conlleva, entre otros efectos, transformar los flujos financieros del "gasto público" y el "ingreso público" en los flujos económicos del "costo público” y los "recursos públicos”, debiendo realizar para ello el Estado adecuaciones en sus criterios de registración presupuestaria y contable.

En efecto, si aceptamos que la "distancia” entre los flujos financieros y los flujos económicos en un período de tiempo, debe encontrarse en las variaciones de los stocks patrimoniales iniciales y finales de dicho período, cualquiera sea el contenido concreto que le demos al criterio de lo devengado; una transición plena desde los conceptos de gasto e ingreso, hacia los conceptos de costo y recurso, requiere un completo desarrollo de los registros patrimoniales del Sector Público, área que, aún en la actualidad, se encuentra poco avanzada en muchos países del mundo.

El primer problema de la generalización de la base devengado en el Sistema de Cuentas Nacionales, fue la incompatibilidad que se generó hasta 2001 con el Sistema de Finanzas Gubernamentales sostenido por el Fondo Monetario Internacional que se compilaba sobre base de caja. Los grupos de trabajo que discutieron esa incompatibilidad terminaron propiciando la modificación del Sistema de Finanzas Gubernamentales que lo hizo migrar en el 2001 hacia una base devengado. Al ponerse en vigencia el nuevo GFSM 2001, las reglas contables resultaron consistentes en todos los sistemas sobre la base de "accrual accounting". Las ventajas de la utilización de este criterio como base de registración son confirmadas por el texto del documento vigente desde 2001 cuando señala:

"3.41 $\mathrm{Si}$ se utiliza la base devengado, los flujos se registran cuando se crea, transforma, intercambia, transfiere o extingue valor económico. En otras palabras, los efectos de los eventos económicos se registran en el período en el que ocurren, independientemente de que se haya efectuado o esté pendiente el cobro o el pago de efectivo. No obstante, no siempre queda claro el momento en que ocurren los eventos económicos. En

\footnotetext{
${ }^{6}$ Nos dice Las Heras sobre los problemas y a la vez ventajas que genera este trabajo "No son pocas las dificultades en determinar costos en la Administración Central...Aún con esas limitaciones el costeo se justifica...por su importancia en el proceso de toma de decisiones" (Las Heras, 2004: 205)

${ }^{7}$ Definición casi idéntica a la incluida en el punto 3.94 del System of Nacional Accounts (SNA)
} 
general, el momento que se les atribuye es el momento en el cual cambia la propiedad de los bienes, se suministran los servicios, se crea la obligación de pagar impuestos, surge un derecho al pago de una prestación social, o se establece otro derecho incondicional.

3.42 Cuando un evento económico exige un flujo de efectivo subsiguiente, como en el caso de la compra de bienes y servicios a crédito, el espacio de tiempo entre el momento atribuido a un evento sobre la base devengado y el momento del flujo de efectivo se cierra mediante un asiento en las cuentas por cobrar o por pagar. Por ejemplo, si una unidad del gobierno general compra bienes a crédito, ésta registra un débito bajo la cuenta de existencias y un crédito bajo cuentas por pagar cuando se traspasa la propiedad de los bienes. Al efectuarse el pago en efectivo, la unidad del gobierno general registra un débito bajo cuentas por pagar y un crédito bajo efectivo.

3.43 Todos los eventos que conducen a la creación, transformación, intercambio, transferencia o extinción de valor económico se registran sobre la base devengado en el sistema de Estadísticas de Finanzas Públicas. Por consiguiente, todas las transacciones no monetarias se incluyen en las estadísticas compiladas sobre la base devengado.

3.47 El sistema de Estadísticas de Finanzas Públicas utiliza la base devengado, fundamentalmente porque el momento de registro coincide con el momento del flujo efectivo de recursos. Por consiguiente, la base devengado ofrece la mejor estimación del impacto macroeconómico de la política fiscal del gobierno. En el caso de la base caja, el momento de registro puede ser significativamente diferente del momento de las transacciones y actividades económicas a las que está vinculado. Por ejemplo, el interés pagado sobre un bono cupón cero no se registraría hasta el vencimiento del bono, que podría ocurrir muchos años después que se hubiera incurrido en el gasto. Es muy común que con la base vencimiento de pago las transacciones se registren después que los flujos de recursos hayan tenido lugar, aunque en la mayoría de los casos el lapso transcurrido no sería tan largo como el que permite la base caja. Con la base compromiso, el momento de registro será previo al flujo efectivo de recursos.

3.48 La base devengado brinda la información más completa porque registra todos los flujos de recursos, incluidas las transacciones internas, las transacciones en especie y los otros flujos económicos. Asimismo, este registro completo permite la integración de los flujos con las variaciones en el balance. En términos generales, las cuentas que utilizan la base vencimiento de pago, compromiso o caja se encuentran limitadas a las transacciones monetarias. 
3.50 La gestión de la liquidez es crucial para el funcionamiento de cualquier unidad. Sin embargo, no exige el uso de la base caja, ya que la información sobre los flujos de efectivo no se pierde al utilizar la base devengado. Normalmente, se prepara por separado un estado de flujo de efectivo. Es más, con la base caja podría resultar difícil evaluar la solvencia y los flujos de caja futuros, porque no se dispone de información sobre atrasos.

$\cdots$

3.52 Además, los otros grandes sistemas estadísticos macroeconómicos (cuentas nacionales, balanza de pagos, y estadísticas monetarias y financieras) utilizan la base devengado. Por lo tanto, la utilización de la base devengado en el sistema de EFP facilitará enormemente el uso conjunto de estadísticas provenientes de dos sistemas distintos (Manual de Estadísticas de Finanzas Públicas, 2001²).

En la búsqueda de la armonización de todos los sistemas de registro se generó en 2003 un grupo de trabajo con dicho objetivo. En dicho grupo participaron expertos provenientes del Fondo Monetario, la OECD y el IPSASB ${ }^{9}$ en la búsqueda de sistemas comunes para el registro. Su informe final data de 2006, y en concordancia con la evolución existente ratifica el devengamiento ${ }^{10}$ como criterio unificador para la atribución de flujos a períodos (cfr. Fondo Monetario Internacional, 2006).

\section{3) Una primera conclusion sobre el tema}

En resumen, a partir de 2001 todos los sistemas de cuentas nacionales o de "Macrocontabilidad" adoptan el sistema de lo devengado para el registro de sus transacciones y a la vez definen de manera similar dicho concepto.

Sin embargo, siempre es necesario recordar que "devengado" no es un concepto unívoco $^{11}$. Creemos que resultaría un grave error creer que el contenido del "valor económico" mencionado en las normas citadas más arriba, es objetivo, inmutable y superior a cualquier convención en su aplicación concreta. Es cierto que el predominio neoclásico en la actual teoría del valor económico ha determinado que los desarrollos sobre ese concepto se limiten a asimilarlo al de "precio en los mercados", dejando olvidadas en un viejo arcón las discusiones entre marxistas, clásicos y los primeros neoclásicos sobre la esencia del problema del valor.

\footnotetext{
${ }^{8}$ Durante 2010 se ha iniciado el trabajo de actualización del GFSM 2001, principalmente para adaptarlo a los cambios del System of National Accounts 2008. Se planea publicar los resultados en 2012.(Cfr.http://forums.imf.org/gfsm/showthread.php?8Draft-Outline-of-the-Update-of-GFSM-2001)

${ }^{9}$ El IPSASB ha emitido un extenso "research report" sobre el proceso de convergencia que resume los avances de los grupos de trabajo. Cfr. IPSASB, 2005. Los resultados de este trabajo ratifican, en nuestra opinión, la factibilidad y conveniencia de la convergencia entre Macro y Microcontabilidad.

${ }^{10}$ Refiriéndose a las cuentas nacionales los textos señalan: “El criterio básico de valoración es el de devengado, esto es, el de cambio de propiedad en el caso de venta de bienes, prestación en los servicios y obtención en la producción. Por lo expuesto, se hace abstracción del cobro o pago de las transacciones o retribuciones a los factores de la producción. En todo caso, producido el devengamiento (ya sea que se cree, transforme, intercambie o extinga valor económico), siempre existirá un instrumento financiero que genere el derecho y la obligación correspondiente entre las partes" (Propatto, 2004: 39-40).

${ }^{11}$ Sobre la necesidad de dar contenido concreto al principio de lo devengado cfr entre muchos otros Hauque, 2009
} 
Sin embargo, y aunque aceptemos a rajatabla que en la actual teoría económica valor es precio en un mercado, el problema que no se soluciona con esta definición, es el de cuál precio en cuál mercado concretamente hay que utilizar para dar valor a los stocks y a los flujos que intentamos medir ${ }^{12}$. Sin temor a equivocarnos creemos que estas cuestiones resultan muchas veces harto difíciles de resolver, por lo que obviamente pueden llevarnos a distintas conclusiones según el enfoque que utilice el analista. Es así que consideramos que una apelación al concepto de "valor económico", no puede considerarse una fuente de objetividad, ya que el contenido concreto de la creación, la modificación y la extinción del valor económico es, en nuestra opinión, claramente una cuestión convencional. De esta manera nos enfrentaremos a distintos flujos de resultados y de stocks patrimoniales, según las distintas convenciones utilizadas para dar contenido concreto al criterio de devengado en cada caso.

Es importante destacar en resumen que, el registro por lo devengado, tal como concisamente lo señalan los puntos antes citados, mejora la información que brinda el Sector Público por varias razones:

1) La información económica y patrimonial obtenida sobre la base de lo devengado incluye la tradicional información financiera dentro de su contenido. En cambio, a partir de la información financiera no se puede obtener un estado de flujos económicos del Sector Público (cfr. punto 3.50. Manual de Estadísticas de Finanzas Públicas 2001).

2) El registro por lo devengado permite a la vez conocer el análisis de las causas de los cambios de la cuantía y composición del patrimonio del Sector Público, a la vez de permitir el registro de sus componentes. La base caja sólo permite conocer los stocks de medios de pago, mientras que lo devengado nos amplía el panorama a todos los componentes patrimoniales con valor económico. El sistema propuesto es claramente compatible con el registro sobre la base de la partida doble ${ }^{13}$ (cfr. punto 3.42. Manual de Estadísticas de Finanzas Públicas 2001).

3) Las transacciones en las que no intervienen medios de pago, ignoradas por la información de base financiera, también pueden incluirse en el sistema de información pública (cfr. Punto 3.43 Manual de Estadísticas de Finanzas Públicas 2001).

4) El sistema contable del Sector Público se armoniza bajo este criterio con el resto de la información provista por los demás integrantes del sistema económico (cfr. punto 3.52. Manual de Estadísticas de Finanzas Públicas 2001).

\footnotetext{
${ }^{12}$ Mucho más aún en el caso del Sector Público que provee la mayoría de los bienes y servicios que produce a la comunidad a través de mecanismos distintos a los de mercado.

${ }^{13}$ Lo que no significa en modo alguno transformar al Sector Público en un ente cuyo objetivo sea el lucro. Téngase en cuenta que la partida doble es una herramienta muy poderosa que permite compilar información más eficientemente y puede ser utilizada por todo tipo de entes, tengan o no como objetivo el lucro (contra Las Heras, 2004)
} 
Es muy importante destacar que la utilización del criterio de lo devengado no limita sino que enriquece las posibilidades de un sistema presupuestario armonizado con el sistema de información contable público ex post. En efecto, más allá de las consecuencias legales del contenido de la norma de Presupuesto tradicional, resultaría harto conveniente que el Sector Público, pueda brindar información proyectada no sólo en los aspectos financieros, sino también en los económicos y los patrimoniales. Sólo así podremos comparar plenamente los distintos aspectos de la gestión que se proyectaron, con los que efectivamente ocurrieron, para determinar la existencia y cuantía de los posible desvíos.

Mucho más allá de las obligaciones normativas que cada Estado pueda tener para suministrar información, de "lege ferenda" resulta indubitable que ésta resultará mucho más completa si se organiza sobre el registro de lo devengado. Sin que perdamos la información financiera que tradicionalmente brindan los presupuestos y la contabilidad pública sobre los ingresos tributarios y los gastos que su administración genera; avanzaremos hacia un sistema de información que nos brinde los flujos devengados de recursos tributarios y de sus costos asociados, complementado por la información patrimonial que se desprende de los mismos.

No nos quedan dudas de que este camino no es fácil. El proceso de "transition to accrual" resulta dificultoso, ya que implica fuertes cambios en todo el sistema de captura, procesamiento y exposición de la información en el Sector Público. Muchos más datos deben obtenerse y muchos nuevos procesos deben llevarse a cabo. En dicho tránsito se observa que las adecuaciones relacionadas con los flujos de egresos resultan en general menos traumáticas que las que atañen a los flujos de ingresos, en especial los de fuente tributaria ${ }^{14}$.

Está claro, sin embargo, que no descubriremos todos los “costos ocultos"15 de los sistemas tributarios mediante el simple expediente de utilizar el criterio de lo devengado. Deberemos además tomar en cuenta el contenido económico más amplio del concepto "costo", e intentar con ello definir lo más concretamente posible los distintos capítulos que lo conforman para el caso que nos ocupa.

\section{c) Los costos del sistema tributario}

\section{1) LAS CATEGORÍAS DE COSTOS BAJO ANÁLISIS}

Además de la necesidad de transformar a nuestros efectos el tradicional concepto de "gasto" erogado o comprometido al de "costo" devengado, nuestro estudio requiere la utilización de categorías específicas dentro de dicho concepto, algunas atribuibles a la Economía y

\footnotetext{
${ }_{14}$ Sobre este tema cfr. entre otros Hauque y Cataneo, 2006. Si el lector tomó conciencia luego de la lectura de estos textos normativos de las complicaciones concretas que genera la determinación de los recursos tributarios devengados de un Sector Público, cuando el ejercicio es anual, deberá tener en cuenta que las cuentas nacionales y públicas de los países centrales tienden actualmente a ser realizadas sobre períodos menores (por ejemplo cuatrimestrales), por lo que los problemas de "momento de reconocimiento" se multiplican.(cfr. Instituto de Estadística Francia, 2007)

${ }^{15}$ Uno de los posibles usos de la información sobre "costos" del sistema tributario, resultará en su utilización en los casos de las tasas del Sector Público, en las que su cuantía, según la doctrina, debe mantener una relación "razonable" con el costo del servicio que financian. Resulta evidente que el monto de la tasa deberá permitir soportar no sólo el costo del servicio que se pone a disposición, sino también los costos directos que genera el proceso de su imposición.
} 
otras provenientes de la Contabilidad de Gestión. Demás está decir que su diverso origen no obsta a su utilización en el campo del Sector Público.

El lector podrá sorprenderse al observar que se proponga la utilización de categorías utilizadas por especialistas de otras disciplinas, para completar la información provista por el Sector Público. Es así. Siempre hemos sostenido que muchas herramientas técnicas tienen usos poco conocidos aún por sus propios constructores. Ello no puede ser óbice para su utilización en todos los ámbitos en las que resulten aplicables. El Sector Público puede y debe utilizar todas las herramientas útiles, sin importar su origen, teniendo en cuenta que en términos económicos y administrativos, es ni más ni menos que una gigantesca organización destinada a producir bienes y servicios para la comunidad.

Recordemos que esta interacción es recíproca ya que “...el secreto mejor mantenido en la gestión empresaria es que las primeras aplicaciones sistemáticas de la teoría de la gestión empresaria y los primeros principios de la administración no tuvieron lugar en la empresa privada. Se desarrollaron en el sector público...” (Drucker citado en Las Heras, 2004: 49).

La utilización de los "costos"16 no sólo mejora la información provista por permitirnos avanzar hacia lo devengado, sino también nos permite direccionarnos hacia el análisis del producto público. En efecto, para transformar los "gastos" en "costos" debemos tener claro el "para qué bienes y servicios" se efectúan los gastos y atribuirlos en función de los mismos. La programación del presupuesto está íntimamente ligada a este proceso ya que "(l)a programación presupuestaria requiere...la asignación de créditos financieros (para) el costeo de las distintas categorías programáticas en función de las acciones a realizar" (Las Heras, 2004: 201).

Repasemos a continuación las categorías que utilizaremos a lo largo de este trabajo.

\section{a) Los Costos de Oportunidad como costo social total}

El enfoque económico del concepto de "costo" se concentra en la noción de "costo de oportunidad" o costo alternativo, como magnitud representativa del sacrificio realizado por la comunidad como un todo para lograr un determinado objetivo.

"A menudo se piensa que los costos en que incurre una empresa incluyen solo los desembolsos de dinero que debe efectuar la empresa para obtener el uso de recursos. Sin embargo, los desembolsos de dinero de una empresa son sólo una parte del cuadro de costos. En muchos casos, los economistas están interesados en los costos sociales de la producción, los costos en los que incurre la sociedad cuando se utilizan para fabricar una mercancía dada. Como los recursos económicos son, por definición, limitados, cuando se utilizan recursos para producir un cierto producto, se podrá utilizar menos de algún otro producto de lo que se podría, si pudieran utilizarse esos recursos en su producción... Según la definición del economista, el costo de producir un cierto producto es el valor de los otros productos que podrían haberse producido con los

\footnotetext{
16 "No se ha mensurado debidamente la importancia del costeo en el sector público...El costeo en la Administración Pública no
} debe considerarse como una tarea ad hoc, sino integrada con el propio sistema de información financiera" (Las Heras, 2004: 202) 
recursos utilizados en la producción del primero...Se llama a esta doctrina, la doctrina del costo alternativo o del costo de oportunidad (Mansfield, 1994: 189) ${ }^{17}$.

Esta noción de costo como valorización del sacrificio de recursos que pudieron haberse utilizado en fines alternativos, es la que informa al sistema de cuentas nacionales. Muchas veces resulta de difícil cuantificación concreta, pero permite identificar "sacrificios" que no se observan cuando nos limitamos al análisis de las cifras erogadas.

b) La diferenciación entre costos externos y privados o "internos":

Dentro de los costos sociales totales, los economistas reconocen dos categorías. Una es la de los llamados costos privados o "internos", que son efectivamente soportados por quién produce los bienes y servicios.

"Los costos sociales para producir una mercancía dada no siempre son iguales a los costos privados, los cuales se definen como los costos para el productor (Mansfield, 1994: 192) ${ }^{18}$

Además existen costos externos, generados por el comportamiento del productor, pero sin que éste efectivamente los soporte ${ }^{19}$.

"Un coste externo es un coste que un individuo o una empresa impone a otros sin que estos reciban nada a cambio" (Krugman y Wells, 2006: 458)

En consecuencia, el costo social total surge de la sumatoria de los costos "internos" que soporta efectivamente el productor de los bienes y servicios en cuestión, más los costos que este productor impone a terceros por ese hecho.

El caso del Sector Público como ente productor no modifica esta categorización. Sin embargo, es necesario señalar que resulta el actor económico que produce mayores efectos externos a través de su actuación en los sistemas económicos modernos ${ }^{20}$.

\footnotetext{
${ }^{17}$ Más allá de los aparentes defectos de traducción que se observan en el texto, la repetida utilización de la palabra "producto" y de sus derivados, nos recuerdan la necesidad de ligar los flujos negativos con los bienes y servicios concretos que aquellos generan para poder conformar el verdadero "costo", sin que interese si nos encontramos en una empresa privada con fin de lucro, en una organización no gubernamental con fines de bien común o en el Sector Público.

${ }^{18} \mathrm{~A}$ lo largo de este trabajo asimilaremos el concepto de "costo privado" al de "costo interno" dado que dichos costos se encuentran internalizados dentro de la función de costos del ente que genera los bienes y servicios, sean estos entes públicos o privados.

${ }^{19}$ Ejemplo típico de este tipo de costos es la contaminación que realizan algunas empresas sin que deban compensar a quienes sufren sus efectos. En el caso de los recursos públicos el concepto es aplicable cómo veremos más adelante, en otros ejemplos, a los costos de cumplimiento de los obligados tributarios que no están a cargo de las administraciones tributarias.

${ }^{20}$ La casi totalidad de las acciones del Sector Público están dirigidas a producir efectos externos positivos en el sistema económico y social de un país, por lo que avanzar en los distintos modos de reflejar presupuestaria y contablemente estos efectos, permitirá mejorar el proceso decisional de los ciudadanos y del propio Sector Público. El caso de los tributos que nos ocupa en este trabajo determina en general efectos externos negativos, razón por la cual hablamos de "costos externos".

Muchos de los esfuerzos de entes privados para reflejar en su sistema contable los resultados de su "responsabilidad social empresaria", implican mecanismos para tratar de integrar a sus sistemas de registro y exposición los efectos externos de las acciones que llevan a cabo. Existe aquí un desafío incitante para profundizar ya que la contabilidad desde antaño se ha concentrado en los efectos que sufre el patrimonio del ente emisor y no los de terceros.
} 
c) Los costos explícitos e implícitos

Recordemos también, para finalizar con los conceptos originados en la ciencia económica, que los costos "privados" o "internos" incluyen conceptos explícitos e implícitos, según si los mismos implican o no egresos efectivos de fondos. Téngase en cuenta, que el "costo de oportunidad" está constituido tanto por costos efectivamente erogados como por renuncias a recursos.

"Un coste explícito es aquel que requiere un desembolso de dinero...Un costo implícito, por otro lado, no implica un desembolso de dinero; en su lugar, se mide por el valor, en términos monetarios de todos los beneficios que se pierden” (Krugman y Wells, 2006: 161).

Los costos explícitos internos han sido tenidos en cuenta desde antaño en los presupuestos públicos como flujos de gastos, mientras que los implícitos y los sociales han merecido sólo tratamientos marginales.

d) La limitación a los costos directos

Nos limitaremos en nuestro análisis a los "costos directos" de la tributación, conforme una clasificación según el objeto del costo. Según la propuesta del Instituto Argentino de Profesores Universitarios de $\operatorname{Costos}^{21}$ es posible considerar al sistema tributario como un "objeto de costo" ya que "...Por objeto de costo se entiende todo aquello cuyo costo se desea conocer. Pueden ser objetos de costo, entre otros: una decisión, una unidad de producto, una línea de producto, un proceso productivo, una etapa de la cadena de valor, un canal de comercialización, una etapa en la función de adquisición, un área de administración, una línea de financiación”.

Así según dicha propuesta los "Costos directos: Son aquellos que, por su naturaleza, pueden vincularse cualitativa y cuantitativamente, en forma inequívoca y excluyente, con un objeto de costos. Esta vinculación se basa en una decisión económico-técnica”. Serán entonces costos del sistema tributario aquellos vinculados inequívoca y excluyentemente con dicho sistema ${ }^{22}$.

\section{2) EL COSTO INTERNO DE LA ADMINISTRACIÓN TRIBUTARIA.}

Tradicionalmente el Sector Público ha reconocido en sus presupuestos como costos directos de la tributación sólo a aquellos ligados a la función de administración tributaria. Es necesario destacar que, a pesar de que el Sector Público no tenga una "función de comercialización" afín a la que se encuentra en las organizaciones que proveen bienes y servicios en el mercado, sus actividades para obtener recursos determinan un conjunto de actividades y costos, parcialmente

\footnotetext{
${ }^{21}$ Propuesta de definición realizada por el Instituto Argentino de Profesores Universitarios de Costos durante 2011 en la búsqueda de estandarizar los contenidos de las distintas categorías de costos (cfr.www.iapuco.org.ar)

${ }^{22}$ Este concepto está dirigido esencialmente a limitar de algún modo el objeto de nuestro trabajo. En una visión extrema, la relación causal entre costo y sistema tributario puede extenderse en forma indirecta a cualquier componente del Sector Público, llegando quizás a considerar la necesidad de prorratear "hacia" el objeto "sistema tributario" costos tan indirectos como podría serlo la remuneración del titular del Poder Ejecutivo.
} 
equivalentes a los que se generan por las relaciones de una empresa con sus clientes ${ }^{23}$.

Los costos internos y explícitos generados por los organismos de administración tributaria han sido desde siempre incluidos como flujo de gastos en todos los sistemas de presupuesto y contabilidad públicos. No hay error en este criterio. Sin embargo, nos equivocamos si consideramos que éstos son los únicos costos del sistema tributario.

“...it has been common practice in the literature to restrict administrative costs to the costs that relate to the running of the revenue departments, but there is no inherent reason (other than simplicity of measurement) why this should be the case. Certainly, there are strong grounds for including legislative and juridical costs in calculations of administrative costs, where they are available and where they clearly relate to the governmental costs of administering the tax system" (ha sido una práctica común en la literatura restringir los costos administrativos a los costos que se relacionan con las agencias de recaudación, pero no hay ninguna razón evidente (más allá de la facilidad en la medición) por la que ésto deba ser así. Ciertamente existen fuertes fundamentos para incluir los costos legislativos y judiciales en el cálculo de los costos administrativos, cuando éstos están disponibles y en los casos en que se relacionen claramente con los costos gubernamentales para administrar el sistema tributario) (Evans, 2001: 5. La traducción es propia) ${ }^{24}$

Aún con la limitación marcada por el criterio de determinar aquí sólo costos directos, si nuestro objeto de costos resulta el "sistema tributario", será necesario agregar los costos legislativos y judiciales mencionados por Evans, pero también adicionar todos los costos destinados a la creación de las normas tributarias, la determinación de los tributos, su cobro compulsivo y otras actividades similares que se encuentran diseminadas en otros organismos del propio Poder Ejecutivo, distintos a la oficina o agencia de recaudación.

Se deberán incluir también en este rubro los costos explícitos del “enforcement” realizado por el Sector Público, ya que "el gobierno debe establecer cuantos recursos destina a combatir la evasión e imponer penas” (Argañaraz et al, 2005: 17).

\section{3).- LOS COSTOS DE LA POLÍTICA TRIBUTARIA, LA EVASIÓN, LA ELUSIÓN Y LA MORA}

La utilización combinada de las categorías descriptas en el punto $\mathrm{C}$ 1) de este trabajo, nos permitirán "desglosar" algunos costos que se mantenían ocultos en un contexto de información de carácter únicamente financiero. En efecto, la noción de costo de oportunidad para toda la sociedad devengado por un período, nos permite mostrar separadamente estos conceptos, comple-

\footnotetext{
${ }^{23}$ Las nuevas tendencias en administración tributaria tienden a asimilar al "contribuyente" con un verdadero "cliente" de la agencia encargada de la recaudación de impuestos.

24 Muchas veces el criterio para registrar un determinado rubro o para exponerlo de manera más explícita resulta el de "availability" o "disponibilidad" del dato discriminado. Esto nos remite al principio básico de "productividad" de la información debiendo comparar para ello el costo de producirla con los beneficios de su utilización. Tengamos en cuenta que la revolución informática desde finales del Siglo XX ha reducido los costos de manera muy significativa y que el Sector Público representa una cada vez mayor parte del producto de un país, por lo que lo quizás lo que hasta hace unas décadas no era conveniente de generar hoy resulta harto productivo.
} 
jizando pero a la vez enriqueciendo la información que se obtiene sobre los recursos tributarios.

Es así que, el cuadro se completa en su totalidad si aceptamos que el devengamiento de los tributos se produce en los períodos en los que se configura su hecho imponible ${ }^{25}$, es decir "llenamos" el criterio de devengado para el reflejo de los recursos tributarios con este contenido; paradójicamente descubriremos nuevos costos a través de la información sobre los ingresos tributarios devenidos en recursos devengados.

Desde este punto de vista, en el período en que se efectiviza el hecho imponible del tributo, éste debería "nacer" para la información presupuestaria y contable. Es en esos períodos en los que la microcontabilidad privada registra los cargos por tributos ${ }^{26}$.

En términos de las normas de cuentas nacionales, es el momento que más se adecua al "full accrual accounting”. El problema es que no resulta fácil para el Sector Público conocer el monto de los impuestos "nacidos", si éstos no son declarados inmediatamente por los obligados tributarios ${ }^{27}$. Es obvio que muchos de los tributos que deberían pagarse, ni siquiera se declaran. Existen estimaciones sobre la evasión tributaria, pero muchas veces no tienen la confiabilidad que las normas presupuestarias y contables requieren para su consideración en informes de uso externo. Sin embargo, no por ello debemos pensar que es imposible contar con dicha información en cualquier tiempo o espacio, por lo que debemos aceptar que resulta posible construir un sistema de presupuesto y registro contable sobre la base del momento de acaecimiento del hecho imponible.

Requeriremos entonces para el conjunto de tributos correspondiente a un período X, que el Sector Público cuente con una estimación suficientemente confiable del total de tributos que potencialmente deberían determinarse por hechos imponibles que se perfeccionarán durante ese período.

\footnotetext{
${ }^{25}$ Sobre las distintas opciones con las que podemos "llenar" el concepto de devengado para los recursos tributarios del Sector Público cfr. entre otros Hauque, 2009. El IPSAS 23 emitido por el IPSASB referido especialmente a tributos y transferencias, se vuelca claramente por la opción del devengamiento sobre la base de la ocurrencia del "taxable event" cuando señala:

"59. An entity shall recognize an asset in respect of taxes when the taxable event occurs and the asset recognition criteria are met. (Un ente debe reconocer un activo en referencia a tributes cuando ocurre el hecho imponible y se cumplen los criterios de reconocimiento de activos)...

66. ....Advance receipts in respect of taxes are not fundamentally different from other advance receipts, so a liability is recognized until the taxable event occurs. When the taxable event occurs, the liability is discharged and revenue is recognized. (...los anticipos en referencia a tributos no difieren significativamente de otros cobros anticipados, por lo que se registra un pasivo hasta que ocurra el hecho imponible. Cuando esto sucede, el pasivo se cancela y se registra el recurso)...

68. ...Where there is a separation between the timing of the taxable event and collection of taxes, public sector entities may reliably measure assets arising from taxation transactions by using, for example, statistical models based on the history of collecting the particular tax in prior periods.(...Cuando exista separación entre el momento de la ocurrencia del hecho imponible y la recaudación del tributo, el sector público puede medir confiablemente los activos que surjan de los tributos utilizando por ejemplo modelos estadísticos basados en los antecedentes de recaudación de ese tributo en períodos anteriores)" (IPSAS Nro. 23 - La traducción es nuestra) No hay dudas que el criterio que aquí sostenemos es el que genera mayores dificultades prácticas para la realización de las estimaciones de valores concretos. Es así que en la Argentina en la actualidad, el marco conceptual vigente a través del punto 7.5.5.a) de la Recomendación Técnica Nro. 1 del Sector Público, considera al momento del origen del crédito del Fisco, como el determinante para el devengamiento de un recurso tributario. Sin embargo, el contenido de esta norma representó un gran avance desde el tradicional reconocimiento en el momento de la recaudación, y marca, en nuestra opinión, un hito transicional en un camino de convergencia hacia el criterio del IPSAS 23.

${ }^{26}$ Realizando muchas veces sutiles análisis para el caso del impuesto sobre la renta, determinando aún activos y/o pasivos por la utilización del método del impuesto diferido.

${ }^{27}$ Específicamente en los tributos de autodeterminación cuyos montos surgen de declaraciones juradas presentadas por los obligados tributarios.
} 
En teoría, ese monto debería ser, más tarde o más temprano recaudado. Sin embargo, sabemos que no todos esos recursos se transformarán en flujos de fondos en el futuro, parte por falta de declaración -y obviamente de pago- (evasión) y otra parte, simplemente por falta de pago aunque haya existido su declaración (impago o incobrabilidad).

La microcontabilidad privada tiene experiencia en el reflejo de estimaciones de impagos futuros de créditos presentes a través del uso de la Previsión para créditos incobrables. Podríamos extrapolar esta experiencia para lograr registrar las estimaciones de incobrabilidad de tributos determinados que no se cobrarán (incobrables) y también de tributos que nunca se determinarán (evasión), ajustando así el valor de los activos a una cuantía más acorde con las expectativas de transformación en medios de pago. Tendremos así, en el activo a final de cada período, un monto total de tributos a cobrar coincidente con el total estimado potencial. Sin embargo, estos montos estarían regularizados con dos previsiones: la Previsión para Evasión, reflejando los montos que razonablemente nunca se declararán ni pagarán, y la Previsión para Impagos o Incobrables, que reflejará los montos que declarados, previsiblemente nunca lograrán cobrarse.

Si consideramos que la pérdida por tributos en los entes privados debe reflejarse conforme acaezcan los hechos imponibles, muy sencillo debería ser aceptar que los entes públicos deberán reflejar correlativamente el recurso correspondiente regularizado por las previsiones de evasión e incobrabilidad antes citadas, en un contexto de armonización de criterios de imputación a períodos. A pesar de que no es fácil cumplir con la condición de obtener una cuantificación objetiva y verificable de sus montos, las estimaciones que posean un nivel razonable de confiabilidad podrán utilizarse válidamente. Tengamos en cuenta que en el campo de la presupuestación de recursos el sistema actual se basa únicamente en estimaciones financieras de recaudación neta. La inclusión de este mecanismo en el ámbito del presupuesto de recursos solo implicará la necesidad de estimar montos brutos, y detraer de ellos otras estimaciones respecto de la evasión y de los incobrables ${ }^{28}$.

Existen versiones limitadas de esta opción. Aquellos que estén de acuerdo con que no deben registrarse los tributos que nunca se revelarán al Fisco, no estarán dispuestos a aceptar que se consideren "ganados" montos que seguramente serán evadidos ${ }^{29}$. De esta forma, no presupuestarán ${ }^{30}$ ni el recurso evadido, ni el quebranto estimado por la previsión para evasión. El lector avezado observará que este sistema "birla" al usuario la estimación del dato de los montos evadidos, que desaparece como por arte de magia del presupuesto y los registros con-

\footnotetext{
${ }^{28}$ Más difícil quizás resulte el trabajo en el sistema de contabilidad ex post. Sin embargo que un trabajo sea difícil, no quiere decir que no valga la pena acometerlo.

${ }^{29}$ En palabras del IPSASB "However, recording accrued amounts of taxes - at the time they are due or generated - should not lead to recording amounts that are known to be uncollectible, or are unlikely to be collected. Furthermore, the balancing item of the general government sector should not be artificially improved by the recording of amounts of taxes which are never collected." (Sin embargo, registrar los montos de tributos devengados -en el momento en el que vencen o se generan - no debe conducir a registrar montos que se reconozcan como no recaudables o que probablemente no podrán ser recaudados. Más aún, los resultados del sector gobierno en general no deben ser artificialmente mejorados a través del registro de tributos que nunca serán recaudados) (IPSAS 23 - La traducción es propia). Hay que tener en cuenta que ratificamos plenamente este criterio. Simplemente proponemos que la información de dichos montos se exponga en forma completa, mostrando separadamente los montos "brutos" de tributos que debieran haberse colectado menos los "costos" de la evasión y la incobrabilidad.

${ }^{30} \mathrm{Y}$ tampoco lo registrarán en el sistema contable que se integre al presupuestario.
} 
tables a través de una “compensación”. Nadie podrá así evaluar si ex post se logran reducciones en los niveles de evasión previstos ex ante a través del contraste con los registros contables integrados al presupuesto. En este sentido, consideramos que si la evasión es un fenómeno económico significativo, debería intentar reflejarse en el sistema presupuestario y contable del Sector Público. Recordemos siempre que cuando decidimos no informar sobre determinadas variables económicas, en este caso la evasión, estamos estableciendo una presunción implícita de que dicha variable tiene un valor igual a cero. Y si de algo estamos seguros es que el nivel de evasión de tributos no es cero en ningún país del mundo.

Es necesario aclarar a esta altura que las propuestas para "regularizar" los montos devengados a través de previsiones no buscan transplantar mecanismos "microcontables" privados al sistema público sin la necesaria adecuación a un esquema normativo esencialmente diferenciado. Será necesario tener en cuenta que la información contable pública deberá precisar, conjuntamente con la metodología de estimación utilizada, que los créditos registrados en este momento no tienen la misma probabilidad de cobro que un derecho cierto y que ni siquiera tienen individualizado al deudor concreto de la obligación, para evitar inducir a error a los usuarios de la información.

A esta altura es importante recordar que los textos de Finanzas Públicas y de Derecho Financiero se encargan de destacar las diferencias que se marcan en el proceso presupuestario para los recursos y los gastos públicos

“Así como para los gastos el presupuesto autoriza y limita...para los recursos carece de esos dos caracteres. La facultad para recaudar determinados ingresos no emerge de la ley de presupuesto, sino de las leyes tributarias creadoras de fuentes de ingresos públicos. El cálculo de recursos tampoco es limitativo; sólo reviste carácter estimativo" (Atchabaian, 2008: 161).

Esta conformación del proceso genera las siguientes consecuencias sobre los flujos de recursos y gastos:

a) Los montos de recursos presupuestados, esencialmente tributarios, reflejan sólo una estimación razonable de los montos a cobrar en concepto de los distintos tributos. Esto es así, ya que la autorización para el cobro de los tributos se otorga al Poder Ejecutivo a través de la vigencia de las leyes que instauran cada uno de ellos. Sin embargo la información que se obtiene tradicionalmente a través de la Cuenta de Inversión no diferencia entre recursos devengados y recursos efectivamente cobrados en el período bajo estudio, por lo que la información patrimonial de créditos del Sector Público relacionada con la gestión tributaria resulta deficiente, obstando al control cabal del Poder Legislativo en relación al mandato de cobro de tributos otorgado en cada una de las leyes que los impusieron. 
b) El concepto y monto de gasto incluido en la ley presupuestaria anual resulta al mismo tiempo que una estimación razonable de los montos a gastar, el límite de la autorización legislativa al Poder Ejecutivo para realizar dichos gastos. A través de la Cuenta de Inversión, el Poder Legislativo debe considerar los montos de gastos devengados por el período precitado, al mismo tiempo que conoce los montos efectivamente pagados por cada concepto, pudiendo compararlos con los autorizados en el presupuesto y analizar los llamados "residuos pasivos" que se generan ante gastos devengados y no pagados.

Uno de los principales inconvenientes de la explicitación de costos como el de la evasión en el proceso presupuestario, resultará el evidente hecho de que el Poder Legislativo no puede "autorizar" oficialmente al Poder Ejecutivo a soportar un monto determinado de tributos evadidos. Sin embargo, volvemos a llamar la atención respecto de que la información sobre base "devengado" debe considerarse como complementaria a la tradicional presupuestación financiera y no como su sustituto. Sin necesidad de que la ley "autorice” al Poder Ejecutivo a soportar un nivel dado de evasión, contar con dicha estimación a priori y poder contrastarla con los datos ex post, permitirá que los legisladores y la sociedad puedan evaluar mucho más correctamente la acción del Sector Público.

En este sentido, y en la búsqueda de un resumen de los costos "descubiertos" en esta visión, resulta pertinente recordar que es tradicional en la literatura sobre administración tributaria analizar su desempeño sobre la base de las llamadas "brechas" de mora y evasión respecto de los montos recaudados. Ahora bien, este esquema puede ser completado para incluir la totalidad de los flujos positivos y negativos que con criterios de "costo de oportunidad" debemos considerar a los efectos de los recursos tributarios y de sus costos directos asociados, si le incorporamos los costos que implican los llamados "gastos tributarios" por los economistas.

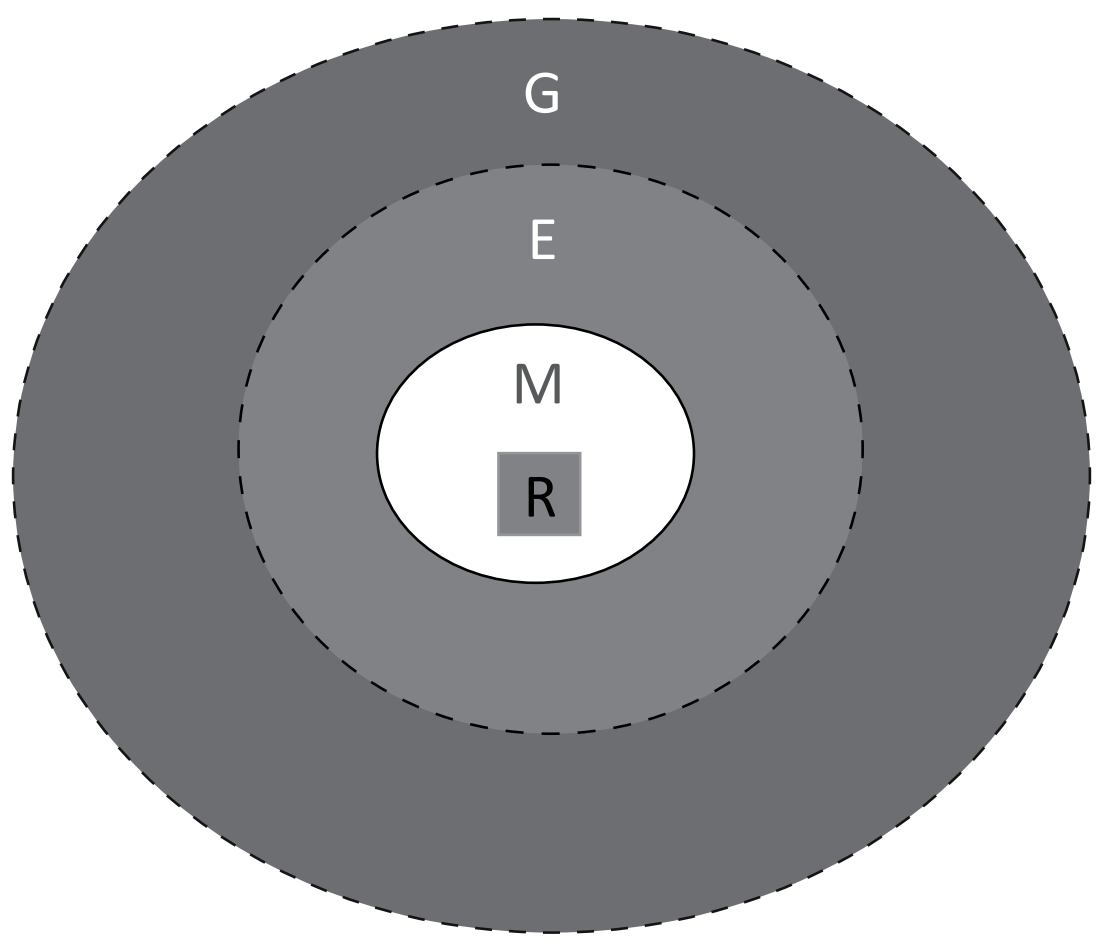


Intentemos a continuación explicar el significado del gráfico ${ }^{31}$ :

Los "círculos" mayores de la "política tributaria"

- El marco total de las posibilidades de ejercicio de las potestades tributarias dentro de la Constitución y otras normas supralegales como los tratados internacionales, está demarcado por el círculo más amplio, más allá de que las mismas se ejerzan efectivamente a través de leyes tributarias concretas o no. Su borde se encuentra punteado ya que no resulta sencilla una demarcación exacta de su cuantía total, sino que deberemos estimarla ${ }^{32}$. La cuantía total de los recursos a obtener conforme la política tributaria conformada por leyes vigentes, determina el contenido del siguiente círculo incluido dentro del más amplio. Se encuentra aquí el producido de la totalidad de los hechos imponibles que las leyes tributarias mandan efectivamente al Fisco determinar y recaudar, más allá de que efectivamente lo sean. El borde de esta área también está demarcada con un punteado, ya que la correcta definición de todos los hechos imponibles del sistema muchas veces se encuentra difusa por el fenómeno de la elusión tributaria. Nos encontramos aquí ante el límite tradicional entre la "política tributaria" y la "administración tributaria".

- La diferencia entre las dos primeras áreas resultaría una cuantificación amplia posible de los llamados "gastos tributarios" (G) ${ }^{33}$ en Economía del Sector Público, ya que surgen de un ejercicio del poder tributario que el sistema constitucional permite, pero que el Poder Legislativo voluntariamente se abstiene de realizar $^{34}$.

- Más allá de que la tradicional definición de "gasto tributario" considera un impuesto de referencia o "benchmark" como elemento a comparar con el impuesto efectivamente legislado (cfr. Villela et al, 2009: 5), en nuestro análisis el "costo de oportunidad de la política tributaria" estará dado por todos los tributos que podrían ser legislados en el marco constitucional vigente y no han sido impuestos efectivamente, por una decisión explícita ${ }^{35} \mathrm{o}$ implícita ${ }^{36}$ del órgano legislativo. De esta manera estaríamos midiendo la "renuncia tributaria" legislativa total de un sistema tributario en un período dado.

\footnotetext{
${ }^{31}$ El gráfico no se encuentra dibujado a escala.

${ }^{32}$ Los profesionales en Ciencias Económicas no debemos "asustarnos", aún en el marco de nuestra actuación en el Sector Público, por encontrarnos obligados a estimar valores fundadamente. Tengamos siempre en cuenta que ningún valor presupuestario es "exacto". Ni siquiera los informes contables ex post, sean privados o públicos, incluyen información que pueda considerase "exacta" sino que abarca sólo "representaciones razonables" de la realidad.

${ }^{33}$ En el contexto de nuestro trabajo en que utilizamos el criterio de lo devengado como regla, hablaremos de "costos de la política tributaria".

${ }^{34}$ Dice Nuñez Miñana al intentar definir los gastos tributarios en el caso de Impuesto a la Renta: "se ha postulado la conveniencia de reconocer y cuantificar explícitamente estos "gastos impositivos" (tax expenditures); (ya que) desde el punto de vista práctico, estos subsidios implícitos otorgados a través de deducciones o exenciones de cualquier índole serían equivalentes a cobrar en su totalidad los impuestos y con la recaudación hacer frente a gastos explícitos con la misma finalidad" (Nuñez Miñana, 1998: 213). También se los ha definido como "aquellos gastos del gobierno realizados por medio de disposiciones de la legislación tributaria, reglamentos y práctica que reducen o postergan el impuesto para un parte de los contribuyentes" (Villela et al, 2009).

${ }^{35}$ Exención establecida por ley formal.

${ }^{36}$ Inexistencia de ley formal que grave un hecho imponible que podría ser objeto de imposición dentro del sistema constitucional.
} 
- La necesidad de integrar este concepto en sus distintas versiones al proceso de formulación presupuestaria ha sido reconocida por la OCDE y por la casi totalidad de los investigadores en la temática (Ob.cit.: 46 y ssig). Existen distintos sistemas de referencia y su determinación puede ser realizada por distintos métodos compatibles con el criterio de lo devengado (Ob.cit: 26 y ssig). Las principales objeciones se encuentran en las dificultades de su aplicación práctica. Surge otra vez ante nosotros, como seguiremos observando a lo largo de este trabajo, que en este campo se aplica a cada momento aquella vieja locución latina "Video meliora proboque, deteriora sequor".

- Un caso especial de decisiones legislativas que generan "costos de política tributaria", son las frecuentes moratorias y blanqueos que periódicamente se ofrecen en muchos países ${ }^{37}$. Si presupuestamos financieramente implantar una moratoria o blanqueo en un período futuro, los ingresos tributarios supuestamente aumentarán. Sin embargo, ningún ítem de los presupuestos tradicionales nos informará que en realidad los costos tributarios aumentan por las condonaciones otorgadas por estas normativas especiales. Una "amnistía fiscal", sea esta de la forma de moratoria o de "blanqueo", implica, en términos económicos, una transferencia del Sector Público hacia quienes regularizan su situación impositiva en este marco. Es asimilable así a una subvención, por lo que puede ser considerada un verdadero "costo tributario" interno para el Sector Público, aunque implícito.

El "círculo" menor de la "administración tributaria"

- El campo de la "administración tributaria" se observa especialmente desde el círculo de menor radio, que incluye todos los hechos imponibles que se determinan efectivamente por el Fisco o por los propios contribuyentes y llegan por ende a conocimiento del ente de administración tributaria. El área está delimitada con línea llena debido a que no debería haber dudas, en un contexto de una administración tributaria que cumple con sus funciones mínimas, de los montos efectivamente determinados a favor del Fisco. La diferencia con el área descripta en el punto anterior está constituida por la evasión tributaria (E). Podremos discutir sobre su cuantificación, pero no podremos disentir en que la evasión es un costo de oportunidad para el Sector Público asociado directamente al sistema tributario.

- En este sentido, y teniendo en cuenta que muchas veces las acciones de administración tributaria en nuestros países tienen más significación práctica que las relacionadas con la política tributaria, recordamos que “...quizás el hecho más notable de toda la literatura tributaria, no sólo la referida al Impuesto al Valor Agregado, es la casi total ausencia del análisis de los incentivos a recaudar (Llach, 2001)". Esto es así, ya que sólo se tienen en cuenta en los análisis de los sistemas de recursos los montos recaudados o a recaudar efectivamente, desde un punto de vista exclusivamente financiero, sin tener en cuenta todos los “costos de oportunidad" de dicha recaudación.

${ }^{37}$ Para Argentina la última norma en este sentido a nivel nacional resultó la ley 26.476 que tuvo efectos hasta el año 2010. 
- El cuadrado del centro engloba los hechos imponibles respecto de los que efectivamente se produjo la recaudación de tributos (R). La diferencia con el área anterior resulta de restar del total de tributos determinados por el período, los efectivamente recaudados por el mismo período, lo que tradicionalmente se simboliza como mora $(\mathrm{M})^{38}$.

- Destaquemos que la Mora no es en sí un "costo" tributario. Si lo son los tributos que habiendo sido determinados, nunca son cobrados por el Sector Público: los "incobrables". También generarán resultados por la mora los cargos financieros en términos reales que el sistema tributario determine sobre sus activos y pasivos $^{39}$.

- El cuadrado "R" tiene doble línea en sus bordes para resaltar que su contenido es el único concepto de los aquí explicitados que se muestra actualmente en el presupuesto y la contabilidad pública. Allí están los montos recaudados o los ingresos financieros por tributos en el Sector Público. Estos montos son "costos internos o privados" de los obligados tributarios, pero "recursos" del Sector Público, por lo que no constituyen costos para la sociedad en su conjunto, sino una verdadera transferencia de recursos.

Existen dificultades especiales en cuanto al registro de los recursos públicos de acuerdo al criterio de lo devengado, pero ninguna de ellas justifica el "ocultamiento a través de netos de recaudación” de costos que deben ser tomados en cuenta para desempeñar correctamente la función de recaudación.

¿Por qué resulta tan importante el contenido del concepto de "devengado" y el de "costo de oportunidad" para definir el concepto de recurso tributario para nuestro sistema? Precisamente porque será este contenido el que nos permita evitar el "neteo" u "ocultamiento" de verdaderos costos significativos relacionados con la política y la administración tributaria. Al mismo tiempo, nos permitirá reconocer "stocks" de saldos activos y/o pasivos de tributos que la actual Contabilidad Patrimonial del Sector Público no registra plenamente ${ }^{40}$.

\footnotetext{
${ }^{31}$ La utilización del concepto "Mora" no debe confundir al lector, ya que los activos al cierre de período pueden o no ser exigibles jurídicamente a dicha fecha, especialmente si elegimos al hecho imponible como el hecho determinante del devengamiento. Si realizamos un análisis multiperíodo, encontraremos que los montos recaudados en un período determinado, incluyen tributos devengados en períodos previos que estaban pendientes de pago al inicio del período. En esta perspectiva, para integrar la perspectiva financiera y la económica deberemos considerar las variaciones de activos y/o pasivos por tributos devengados entre el inicio y el cierre del período.

${ }^{39}$ Hablamos también de pasivos para el Sector Público porque la proliferación de sistemas de retenciones, percepciones, recaudaciones, anticipos y pagos a cuenta, determina muchas veces la existencia de saldos a favor y pagos sin causa de los obligados tributarios, que representan claramente pasivos para el Sector Público.

${ }^{40}$ Los argumentos de quienes sostienen el actual sistema de registro de los ingresos tributarios al momento de su percepción están, en nuestra opinión, concentrados en dos elementos centrales. Convencidos de que los mismos no resultan correctos, trataremos de refutarlos a continuación:

a) "Sobre una base de prudencia razonable sólo se puede atribuir un recurso tributario a un período cuando se cobra efectivamente el tributo". Las dificultades para cobrar los tributos determinados y los bajos porcentajes de efectiva recaudación hacen que no pueda considerarse el hecho imponible como el hecho generador del recurso. Más allá de que la decisión sobre cuál resulta el "hecho generador" es, en nuestra opinión, una cuestión convencional a determinar precisamente según la información que buscamos, estamos seguros que la definición que proponemos nos permite acercarnos más a la realidad económica del Sector Público, sin perder la información tradicional. Ninguna empresa cuenta como "cash flow" disponible su resultado económico positivo, porque los decisores diferencian entre los aspectos económicos y los financieros. Lo mismo debería acontecer para el Sector Público

b) “No existen los datos. No es significativa la mejora de la información si los conseguimos, ya que obtenerlos resulta demasiado
} 
Por último, y sin que por esto resulte menos importante, el criterio de lo devengado nos permitirá registrar correctamente las operaciones relacionadas con los tributos que no implican movimiento de medios de pago. En efecto, en el sistema actual que sólo rescata los montos recaudados, no hay posibilidades de exponer presupuestaria y contablemente las compensaciones que muchas veces efectúan los contribuyentes entre sus saldos a favor en el tributo X y los montos a pagar en el tributo $\mathrm{Y}^{41}$. Una correcta imputación de los montos que efectivamente corresponden a cada tributo exige una diferenciación clara en los registros entre la determinación del monto del tributo y sus mecanismos de pago, a través de la utilización del criterio de lo devengado.

\section{4) LOS COSTOS EXTERNOS DEL CUMPLIMIENTO TRIBUTARIO NO INTERNALIZA- DOS POR EL SECTOR PÚBLICO}

Si intentamos descubrir la totalidad de los costos de un sistema tributario, una sección especial la merecen los "costos externos" de la Administración Tributaria ("tax compliance costs"). En efecto, en un sistema en el que prevalecen los tributos de autodeterminación, proliferan los mecanismos "paratributarios" de anticipos, retenciones y percepciones y se multiplican día a día las exigencias formales para con todos los obligados tributarios, los costos de cumplimiento que ha externalizado la Administración Tributaria tienden a ser cada vez más significativos.

Sobre el tema se ha dicho para el caso argentino:

“¿Qué hay respecto a los costos de cumplir con el Fisco? ¿y qué se entiende por costo de cumplir con el Fisco? Son todos aquellos costos directos e indirectos que las empresas tienen que erogar, pago a contadores y abogados por ejemplo, para poder cumplir con el pago de los impuestos....Esto te da en promedio, para todas las firmas, un costo de cumplimiento de $1,8 \%$. Si comparamos cuanto le cuesta a la Administración Federal de Ingresos Públicos (AFIP) recolectar todo lo que recolecta, o sea, lo que gasta la AFIP en presupuesto, dividido lo que recauda, te da 1,6...La razón se debe, no a las empresas grandes, sino que a las empresas chicas les cuesta mucho cumplir con el Fisco... El 1,8 versus el 1,6 es lo que observamos hoy tal como está dado el sistema tributario" (Auguste en Autores Varios, 2006: 125)

En el mismo sentido "tax compliance costs are those costs incurred by taxpayers, or third parties such as bussinesses, in meeting the requirements laid upon them in complying with a given structure and level of tax" (los costos de cumplimiento tributario son aquellos en los que

costoso": Es cierto que si la información sobre posibles ejercicios de potestades tributarias, determinaciones o montos emitidos de tributos no existen o no son mínimamente confiables, nuestra propuesta se torna imposible. Ahora bien, eso no quiere decir que sea utópico o imposible obtener estos datos. Seguramente será una tarea muy difícil, pero allí se encuentra precisamente el desafío de la propuesta que realizamos. La reciente experiencia de la Administración Federal de Ingresos Públicos de la República Argentina en su desarrollo de "cuentas corrientes tributarias" por contribuyente y de un plan de cuentas específico para asientos propios sobre la base de la partida doble, resulta una clara demostración que avanzar en este camino es difícil pero factible.

${ }^{41}$ Téngase en cuenta que ambos tributos, $\mathrm{X}$ e $\mathrm{Y}$, pueden tener distintas afectaciones específicas de sus producidos o diferentes proporciones de distribución dentro de los sistemas de coparticipación de tributos. 
incurren los contribuyentes y otros terceros como los responsables de tributos, para cumplir los requerimientos que se les impusieron para lograr cumplir con una determinada estructura y nivel de un tributo" (Evans, 2001: 5. La traducción es propia).

Es normalmente dificultoso para cualquier ente realizar estimaciones intersubjetivamente comprobables respecto de costos externos en general. Este caso específico no es una excepción, pero existen muchos trabajos en la búsqueda de su cuantificación ${ }^{42}$, a pesar de que en algunos de ellos se entremezclen con los costos externos de eficiencia a los que nos referiremos en el próximo punto (cfr. Evans, 2001: 5-6).

5) LAS DISTORSIONES SOBRE EL SISTEMA PRIVADO. LA FALTA DE NEUTRALIDAD DE LOS TRIBUTOS.

La imposición de tributos genera siempre efectos sobre el sistema de mercado. Más allá de la tradicional búsqueda de la "neutralidad" como objetivo a lograr por el sistema, ningún tributo deja de tener efectos sobre el sector privado. Resulta en general una cuestión opinable la cuantificación concreta de estos efectos para cada sistema tributario, pero la literatura económica nos muestra una inmensa cantidad de ejemplos de tributos "distorsivos" que perjudican la eficiencia del sistema ${ }^{43}$, generando costos que debe soportar el Sector Privado de la economía. En realidad para muchos autores los tributos "neutrales" ${ }^{44}$ son una categoría inexistente:

"All taxes except lump sum tax (being the only neutral tax, although impossible to carry through in practice) introduce distortions to an economic system" (Todos los tributos excepto los de suma fija -siendo los únicos neutrales pero imposible de establecer en la práctica- introducen distorsiones en un sistema económico) (Kesner Skreb, 1999: 146. La traducción es propia).

"'A tax which does not change behaviour towards production or consumption is a neutral tax' If a neutral tax is the desiderata... then this is a recipe for no taxes at all. For the only neutral tax is one with a tax rate of zero - or no tax at all. All other taxes most certainly do 'change behaviour towards production or consumption' from what it would have been in the absence of the tax" (Un impuesto que no modifica el comportamiento en relación a la producción o al consume es un impuesto neutral. Si el impuesto neutral es el objetivo... estamos ante una receta para que no existan impuestos, ya que el único impuesto neutral es el que tiene tasa cero o no

\footnotetext{
42 Entre otros el análisis de Auguste para Argentina mencionado más arriba y Alm (1996) citado por Argañaraz et al, $2005: 17$.

${ }^{43}$ Dentro de la bibliografía de este trabajo recomendamos entre otros Nuñez Miñana, 1998 y Stiglitz, 2003. En este sentido la llamada curva de Laffer y sus supuestos sobre el comportamiento de los contribuyentes afectados por un impuesto a la renta, muestran un claro ejemplo de los posibles efectos negativos de algunos tributos sobre la eficiencia del sistema.

${ }^{44} \mathrm{El}$ análisis microeconómico neoclásico concluye en que los únicos tributos que no afectan las decisiones de los productores son los tributos de suma fija o "lump sum taxes". Sin embargo éstos, a pesar de no alterar el costo marginal, obviamente aumentan el costo fijo medio y total de la empresa. Además este tipo de tributos son de difícil aplicación y están normalmente reñidos con la búsqueda de la equidad en el sistema tributario (Cfr. Argañaraz et al, 2005: 15)
} 
existe. Todos los demás impuestos seguramente modifican el comportamiento en relación con la producción o el consumo de lo que hubiera acontecido en ausencia de impuesto) (Block, s/d: 546. La traducción es propia).

Nuevamente el problema estará en encontrar una estimación intersubjetivamente comprobable de este costo, para lo que la abundante literatura económica sobre el tema propone diversos mecanismos.

6) EL SEÑOREAJE Y LOS EFECTOS DE LOS CAMBIOS EN EL NIVEL GENERAL DE PRECIOS.

Los Estados modernos, a través de sus Bancos Centrales, mantienen el monopolio sobre la emisión de billetes y monedas de curso legal, obteniendo así la posibilidad de "emitir pasivos" con un valor fijo que no devengan intereses. Este mecanismo de financiamiento significa un claro beneficio por la posibilidad de financiarse dentro de ciertos límites sin costos financieros asociados. A esta facultad se la denomina en la literatura económica "señoreaje".

Ahora bien, en contextos en los que existen aumentos permanentes en el nivel general de precios de un sistema económico, la base monetaria del Banco Central no sólo determina el tradicional "señoreaje", sino también el llamado "impuesto inflacionario". En pocas palabras "la pérdida del poder de compra del dinero a causa de la inflación representa lo que se denomina impuesto inflacionario" por lo que "la inflación constituye un impuesto que no ha sido aprobado en votación 45 " (Argañaraz et al, 2005: 19).

Es así que la ganancia por exposición a la inflación de sus pasivos monetarios que obtiene el Banco Central, resulta un verdadero tributo no legislado que soporta el Sector Privado en beneficio del Sector Público, que debería ser informado tanto por el sistema presupuestario como por el sistema de contabilidad pública.

Sin embargo, la inflación no sólo resulta en "recursos" para el Sector Público. Es necesario tener en cuenta que en un contexto en el que se reflejen los saldos patrimoniales de tributos a cobrar en cada inicio de período, dichos créditos generarán resultados por tenencia negativos por efectos de la inflación en los casos en los que los accesorios previstos no alcancen a "cubrir" el deterioro inflacionario ${ }^{46}$.

En todos los casos, debería ser reconocido por los sistemas presupuestario y contable del Sector Público, que los cambios en el nivel general de precios absolutos del sistema económico determinan verdaderos "resultados por tenencia" ${ }^{47}$, que no pueden explicitarse en los sistemas

\footnotetext{
${ }^{45}$ Normalmente con fuertes efectos distorsivos sobre el sistema económico en términos de objetivos de eficiencia y equidad.

${ }^{46}$ Sobre los efectos de los cambios en el nivel general de precios sobre los recursos públicos devengados cfr. entre otros Hauque, 2008. La literatura económica nombra a este efecto, significativo para los casos de alta inflación como el efecto Olivera-Tanzi.

${ }^{47}$ Los resultados por exposición a los cambios en el poder adquisitivo de la moneda no surgen de transacciones con terceros, sino de la simple tenencia de activos y pasivos expuestos. Merecería otro análisis los casos en los que se deberían reconocer los resultados por tenencia que generan los cambios en los precios relativos del sistema.
} 
de información que sólo tienen en cuenta los flujos de medios de pago. La hipótesis de la "constancia de la moneda de cuenta" no se sostiene en contextos de significativa inflación o deflación.

\section{D) UN EJEMPLO PARA REFLEJAR DE LOS COSTOS DEL SISTEMA TRIBUTARIO EN}

\section{EL SISTEMA PRESUPUESTARIO Y CONTABLE DEL SECTOR PÚBLICO}

En resumen, la registración de los recursos sobre la base del criterio de lo devengado, sosteniendo que los tributos son "ganados" en el momento en que se producen los hechos imponibles que autoriza el ordenamiento constitucional y supralegal, conjuntamente con el reconocimiento del conjunto de los "costos de oportunidad" del sistema, permitiría la atribución de los recursos al momento de la creación económica del valor, y a la vez obligaría a explicitar un conjunto de costos que actualmente se encuentran "ocultos" para los sistemas de presupuesto y contabilidad pública.

Estos costos deberían ser reflejados en "renglones" separados, y no directamente "neteados" al presentar montos recaudados. Tengamos en cuenta que sobre el tema la IPSAS 23 emitida por el IPSASB señala expresamente en su punto 71: "Taxation revenue shall be determined at a gross amount. It shall not be reduced for expenses paid through the tax system. (Los recursos tributarios deben ser determinados por sus montos brutos. No deben ser reducidos por los gastos pagados a través del sistema tributario)" (La traducción es propia).

Creemos que un ejemplo numérico simple permitirá al lector comprender mejor las ventajas respecto de la evaluación de la gestión recaudadora tributaria que posee este sistema de registro.

Supongamos que contamos con las siguientes estimaciones ${ }^{48}$ respecto de un sistema tributario en relación con lo que presupuestamos ocurrirá durante el período x. En dicho presupuesto se incluye una previsión de inflación del 25\% por el período ${ }^{49}$.

\begin{tabular}{|l|c|}
\hline 1) Monto total recaudado en el período x & 100 \\
\hline $\begin{array}{l}\text { 2) Monto total de tributos devengados por hechos imponibles acaecidos dentro del } \\
\text { período } x \text {, si suponemos que se hubieran utilizado por el Poder Legislativo la totali- } \\
\text { dad de las potestades tributarias que permite el marco constitucional }\end{array}$ & 400 \\
\hline $\begin{array}{l}\text { 3) Monto total de tributos devengados por hechos imponibles acaecidos dentro del } \\
\text { período x, incluyendo solamente los tributos y hechos imponibles efectivamente en } \\
\text { vigencia por decisión del Poder Legislativo }\end{array}$ & 250 \\
\hline $\begin{array}{l}\text { 4) Montos de tributos respecto de los que se estima no se logrará su efectiva deter- } \\
\text { minación (Evasión) }\end{array}$ & 50 \\
\hline 5) Montos de tributos que se consideran incobrables & 30 \\
\hline 6) Intereses devengados durante el período por tributos impagos & 50 \\
\hline
\end{tabular}

${ }^{48}$ El lector deberá suponer que nos estamos expresando seguramente en miles de millones de la unidad monetaria del país en cuestión.

${ }^{49}$ Para simplificar el ejemplo supondremos un período $\mathrm{x}$ sin subdivisiones internas a los efectos del cálculo de los efectos de la inflación. En ese supuesto consideramos que sólo los saldos al inicio del período son afectados por las variaciones en el poder adquisitivo de la moneda. 


\begin{tabular}{|l|c|}
\hline 7) Costos de cumplimiento tributario sociales no internalizados por el Sector Público & 50 \\
\hline 8) Costos externos “de eficiencia” del sistema tributario & 20 \\
\hline $\begin{array}{l}\text { 9) Ganancia del Banco Central por exposición de la base monetaria a los cambios en } \\
\text { el poder adquisitivo de la moneda }\end{array}$ & 25 \\
\hline 10) Saldos pendientes de cobro al inicio del período $x$ & 125 \\
\hline
\end{tabular}

a) Dentro de un proceso tradicional de formulación presupuestaria, el presupuesto informaría exclusivamente sobre los montos que se estiman se recaudarán en el período x. Es decir, se incluirían dentro de los ingresos financieros diferenciados por cada tributo de origen el total de 100. Si suponemos que el monto recaudado fue gastado por el Sector Público 53 "pari passu" con su obtención, no se observan saldos de caja ni de inicio ni de cierre, habiéndose destinado el total de lo recaudado a distintos conceptos de gasto. En algunos $\operatorname{casos}^{54}$, se incluiría complementariamente un informe sobre los "gastos tributarios" según distintos conceptos concretos que podría resultar en una variable "proxy" a la diferencia entre 400 y 250, representando así un intento de información sobre las "renuncias tributarias" del Poder Legislativo ${ }^{55}$.

b) En el esquema que proponemos, que integra presupuestos económicos, financieros y patrimoniales ${ }^{56}$, la información a producir sería la siguiente ${ }^{57}$ :

\begin{tabular}{|l|c|}
\hline \multicolumn{2}{|c|}{ PRESUPUESTO FINANCIERO POR EL PERÍODO X ${ }^{58}$} \\
\hline Recaudado por tributos en el período X & $100 .-$ \\
\hline Gasto realizado en el período X & $(100 .-)$ \\
\hline Modificación en saldos de medios de pagos por el período X & $0 .-$ \\
\hline
\end{tabular}

\footnotetext{
${ }^{50}$ Véase punto $(4)$ de este trabajo.

${ }^{51}$ Véase punto $C 5$ ) de este trabajo.

${ }^{52}$ Véase punto $(6)$ de este trabajo.

${ }^{53}$ Se incluyen dentro de estos gastos, aquellos costos explícitos generados por la administración y el "enforcement" del sistema tributario (véase punto $\mathrm{C} 2$ ) de este trabajo)

${ }^{54}$ Sobre los países que incluyen un informe sobre "gastos tributarios" véase el cuadro de Villela et al, 2009: 50

${ }^{55}$ Siempre que recordemos que los montos del ejemplo se imputan al período $\mathrm{x}$ sobre base devengado, mientras que los informes de "gastos tributarios" refieren en general a "base caja". Según Villela et al, 2009: 50, sólo en los casos de Australia, Austria, Holanda, Italia y Reino Unido se brinda esta información sobre base devengado.

${ }^{56} \mathrm{El}$ presupuesto financiero incluirá sólo las proyecciones de flujos de medios de pago; el económico los flujos devengados del período considerando que el momento en que se configura el hecho imponible determina la imputación de los recursos tributarios y sus costos asociados mientras que el patrimonial mostrará los activos y pasivos al inicio y cierre de cada período. Salvo causas excepcionales, el flujo neto del presupuesto económico explicará el aumento o disminución del patrimonio entre el inicio y el cierre del período. Para reflejar los cambios en el poder adquisitivo de la moneda suponemos que el "Patrimonio Neto a mantener" es el que resulta de ajustar dicho valor por el índice de variación de precios absolutos escogido a través de la estimación de la inflación del período.

${ }^{57}$ Desde ya debe quedar claro que propugnamos la total integración del sistema presupuestario con el de contabilidad pública, por lo que el sistema de clasificadores y de registración debería replicarse "mutatis mutandis" en el sistema de información contable ex post. El esquema planteado es compatible con un sistema de registración sobre la base de la partida doble.

${ }^{58}$ En esta propuesta, el Presupuesto Financiero resultaría idéntico al tradicional.
} 


\begin{tabular}{|l|c|}
\hline \multicolumn{2}{|c|}{ PRESUPUESTO ECONÓMICO POR EL PERÍODO X } \\
\hline Tributos totales devengados con un uso completo de las potestades constitucionales & $400 .-$ \\
\hline Pérdida estimada por decisiones de política tributaria (“renuncia tributaria”) & $(150 .)^{59}$ \\
\hline Pérdida estimada por evasión & $(50 .-)$ \\
\hline Pérdida estimada por incobrables & $(30 .-)$ \\
\hline $\begin{array}{l}\text { Resultado por exposición a los cambios en el poder adquisitivo y financieros en } \\
\text { términos reales }\end{array}$ & $(25 .)^{60}$ \\
\hline Gastos realizados en el período X61 & $(100 .-)$ \\
\hline Resultado económico & $45 .-$ \\
\hline \multicolumn{1}{|c|}{ PRESUPUESTO PATRIMONIAL AL CIERRE DEL PERÍODO X62 } \\
\hline Saldos a cobrar por tributos & 420. - $^{63}-$ \\
\hline Total Activos & $420 .-$ \\
\hline Patrimonio Neto al inicio ajustado al cierre & $375 .-$ \\
\hline Resultado económico del período x & $45 .-$ \\
\hline Total Patrimonio Neto & $420 .-$ \\
\hline
\end{tabular}

Además en este estadio y como información complementaria se deberían agregar datos sobre otros costos sociales del sistema tributario no internalizados por el Sector Público y los costos del "impuesto inflacionario" surgidos de los Estados Contables del Banco Central:

- Costos de cumplimiento tributario sociales no internalizados por el Sector Público (“compliance costs") estimados en 20.

- Costos sociales generados por los efectos de limitación de eficiencia por el sistema tributario en el sector privado estimados en 25.

- Costo del "impuesto inflacionario" estimado con el cálculo de la ganancia por exposición a los cambios en el poder adquisitivo de la moneda del pasivo monetario del Banco Central soportado por los tenedores de la moneda de curso legal durante el período en cuestión: $125^{64}$.

\footnotetext{
${ }^{59}$ Surge de restar 400 menos 250.

${ }^{60}$ Este monto surge de aplicar el índice de inflación al saldo inicial por tributos a cobrar, lo que arroja un valor de 75.- de pérdida por exposición a las variaciones en el poder adquisitivo de la moneda. A dicho valor debemos restar los intereses devengados de 50.- considerados como "cobertura" de la inflación. De allí surge el neto de 25.-

${ }^{61} \mathrm{~A}$ los efectos de simplificar el ejemplo supondremos que no hay diferencia entre los gastos erogados y los gastos devengados por el período $\mathrm{X}$.

${ }^{62}$ El Estado Patrimonial al inicio del período X en este contexto de simplificación resultaba de 300 en el Activo por los saldos a cobrar por tributos y un Patrimonio Neto de igual monto.

${ }^{63}$ Al saldo inicial de 300 , debemos adicionarle los 250 devengados por tributos y los 50 devengados por intereses. Luego le restaremos los 100 cobrados, los 50 estimados por evasión y los 30 por incobrabilidades. Obtendremos así el valor de 420 . Incluimos en la misma cuenta de activo a los tributos y sus intereses para simplificar la presentación. Los montos detraídos por estimaciones de evasión e incobrabilidad pueden exponerse por separado en cuentas regularizadoras.

${ }^{64}$ Resultaría necesario mostrar este resultado dentro del consolidado de los estados de todos los entes públicos, incluido el Banco Central. Para el ejemplo nos limitamos a señalarlo como un dato complementario.
} 
El sistema contable ex post deberá informar sobre el efectivo cumplimiento de cada uno de estos presupuestos, detectándose en su caso los desvíos que se produzcan. Quedará abierto así el camino para investigar en las posibles causas que los generaron.

\section{E) LA IMPORTANCIA DEL REFLEJO DE LOS COSTOS DEL SISTEMA TRIBUTARIO EN EL SISTEMA PRESUPUESTARIO Y CONTABLE DEL SECTOR PÚBLICO}

Nos parece pertinente para iniciar el camino de la conclusión de este trabajo, reanalizar los efectos de mantener presupuestos y registros contables de los recursos tributarios basados únicamente en el criterio de lo efectivamente recaudado, especialmente desde el punto de vista de su influencia en la toma de decisiones del Sector Público y la Sociedad Civil ${ }^{65}$.

Si sólo se tiene información sobre el cuadrado R, ¿cómo podrá el Poder Legislativo controlar el desempeño de la función ejecutiva en cuanto a la administración tributaria? Si el Presupuesto y la Contabilidad Pública sólo informan los montos recaudados ċcómo podrá la opinión pública evaluar correctamente el desempeño de los funcionarios encargados de recaudar las rentas públicas? El Poder Legislativo mandó a la función ejecutiva a cumplir un programa de recaudación de tributos determinado por el conjunto de leyes impositivas, que al no encontrarse cuantificado en los registros presupuestarios y contables, no permite conocer el peso relativo de las rentas efectivamente recaudadas sobre aquel programa. Mucho más aún, si aceptamos con que en algunos países "la política tributaria es su administración tributaria" (cfr. Bird y Casanegra de Jantscher, 1992), sin esta información ni siquiera conoceremos los lineamientos generales de la verdadera "política tributaria" de ese país. ¿Quién podrá además saber si, a través de compensaciones entre saldos de tributos de algunos contribuyentes, se están coparticipando equivocadamente los montos recaudados?

Tampoco podremos conocer los "costos implícitos" que el sistema genera al mantener ciertos hechos imponibles no gravados o exentos. ¿Cómo podremos evaluar correctamente la política de transferencias de un gobierno, si algunos de ellos están encubiertos y no cuantificados bajo la forma de exenciones impositivas y otros se muestran claramente como pagos explícitos en rubros separados entre los subsidios hacia el sector privado?

Con estimar y registrar sólo el cuadrado R, menos aún tendremos información sobre los "costos externos" que determina el sistema tributario y lo "recaudado" por el "impuesto inflacionario". ¿No sería entonces un comportamiento racional de los funcionarios intentar transferir los costos que actualmente están a su cargo “externalizándolos” hacia los obligados tributarios y maximizar los recursos a obtener por la ganancia por exposición a la inflación de la Base Mone-

\footnotetext{
${ }^{65}$ Creemos además que una importante conclusión general del trabajo es que las distintas ramas de la disciplina contable, tanto en sus aspectos presupuestarios como de registración ex post, tienen mucho que aprender unas de otras. La macrocontabilidad puede obtener de la microcontabilidad privada su experiencia en el manejo de stocks regularizadores de activos, y repensar sus sistemas de registración a partir del concepto de devengado que manejan las cuentas nacionales. La microcontabilidad pública, señera en cuestiones de control administrativo y de manejo de fondos, requiere hoy también de los instrumentos que las demás ramas utilizan desde mucho tiempo atrás. También la microcontabilidad privada podrá abrevar en toda la experiencia que implica el proceso presupuestario público y en su posible integración con los registros ex post. Invitamos al lector a que engrose la lista de contenidos y desarrollos que pueden compartirse.
} 
taria?. En caso de responder afirmativamente la anterior pregunta ¿deseamos realmente que el sistema contenga incentivos para que los funcionarios se comporten de esta manera?

Sin embargo, una de las principales críticas que se puede dirigir a la propuesta aquí esbozada se relaciona con la factibilidad de su puesta en práctica en el corto plazo. Si tan difícil resultó hasta ahora el registro en la etapa de lo devengado de los recursos públicos ¿̇por qué ahora podremos hacerlo sumándolo al reconocimiento pleno de los "costos de oportunidad del sistema"?

Varios argumentos nos señalan un horizonte de esperanza en este sentido, a saber:

a) La permanente revolución informática que permite obtener cada vez más rápido, más información útil a menor costo. En Argentina la inversión realizada por Administración Federal de Ingresos Públicos permitió la difusión del sistema de cuentas tributarias y de un sistema contable interno que puede integrarse con el sistema de administración financiero del Sector Público.

b) La necesidad de tornar lo más transparente posible la gestión y administración de la recaudación de las rentas públicas, para un cabal ejercicio del control ciudadano.

c) Las adecuaciones de las normas legales y profesionales internacionales y nacionales.

d) La posibilidad de avanzar gradualmente en su implementación. Algunas etapas intermedias sugeridas podrían ser, entre otras:

a. Registro del devengamiento de los tributos de liquidación administrativa y de los intereses.

b. Registro del devengamiento de los tributos de autodeterminación en la etapa de la determinación del tributo, ya sea a través de declaraciones juradas o determinaciones de oficio.

c. Depuración periódica sistemática de los créditos tornados incobrables y constitución de previsiones para impagos futuros.

La implementación efectiva del devengamiento en el momento de la configuración del hecho imponible aparece como un objetivo de mediano y largo plazo, difícil de alcanzar en los próximos años, pero que debería resultar el "norte" hacia el cual dirijamos nuestros esfuerzos en la mejora del sistema. Precisamente es el nivel de dificultad del trabajo a realizar, lo que lo torna incitante y desafiante. No encontramos justificativo suficiente para resignarnos eternamente a tomar decisiones sobre la base de información incompleta.

\section{CONCLUSIÓN}

Sostenemos a lo largo de este trabajo que el sistema presupuestario y contable del Sector Público armonizado, debería poder separar los siguientes conceptos que actualmente se encuentran "enmascarados" dentro del neto recaudado, permitiendo así determinar correctamente el flujo completo de recursos tributarios: 
Costos "internos" del Sector Público

1) Los costos representados en los llamados "gastos tributarios": hace ya tiempo que los economistas han aceptado que los tributos no percibidos por exclusiones, exenciones, desgravaciones y deducciones permitidas legalmente son verdaderos costos soportados por el sistema, actualmente no cuantificados plenamente por el sistema presupuestario y contable del Sector Público. Su "separación" como verdaderos costos de la política tributaria resultará indirectamente en una correcta definición de la cuantía de los recursos brutos.

2) Los costos representados por la evasión tributaria: si al menos definimos a los recursos como aquellos devengados al acontecer los "hechos imponibles", deberemos reconocer como costos del sistema a los montos no recaudados en razón de la evasión tributaria. Más allá de las evidentes dificultades para lograr una cuantificación intersubjetivamente comprobable de estos montos, no tenemos dudas de que los costos por evasión distan de ser iguales a cero.

3) Los costos representados por la incobrabilidad efectiva de los tributos y sus accesorios determinados y no cobrados: Los montos de los tributos que en definitiva resultan incobrables por parte del Sector Público son evidentemente costos del sistema, y no deberían simplemente netearse del monto de recursos. Al mismo tiempo, deberán ser informados los resultados financieros en términos reales de la gestión de créditos y deudas tributarias.

Costos "externos" al Sector Público

1) Los costos sociales de recaudación de tributos no internalizados por el Sector Público constituidos por los costos que deben asumir los contribuyentes y demás responsables para el cabal cumplimiento de la normativa impositiva.

2) Los costos sociales de eficiencia de la imposición de tributos que distorsionen en sentido negativo las decisiones de los distintos agentes económicos que participan en un sistema de mercado.

En todos los casos, deberá ser reconocido por los sistemas presupuestario y contable del Sector Público, que los cambios en el nivel general de precios absolutos del sistema económico determinan verdaderos "resultados por tenencia", que no pueden explicitarse en los sistemas de información que sólo tienen en cuenta los flujos de medios de pago. Aquí podremos conocer la cuantía del "impuesto inflacionario", y al mismo tiempo cuantificar los efectos que ese fenómeno produce en los activos y pasivos tributarios que mantiene el Fisco.

Este trabajo intenta ser un elemento que catalice un proceso de discusión doctrinaria sobre los métodos de registro presupuestario y contable de los tributos y su influencia en el logro de una mayor transparencia del sistema de gestión pública. No debería asustarnos que el sistema presupuestario y contable informe periódicamente sobre los montos de tributos que renunciamos a cobrar, que resultan impagos o los quebrantos a asumir por la evasión y la incobrabilidad. Como aprendimos apenas salimos de la infancia, cerrar los ojos no es un método eficaz para evitar problemas que 


\section{efectivamente existen y que deberíamos enfrentar con decisión.}

En esta tarea, hay aún mucho camino que recorrer. El premio a este esfuerzo será que el Estado y la Sociedad Civil contarán con mayor información sobre la gestión de recursos que en algunos países superan en su cuantía el 30\% del valor de su Producto Bruto. ¿No merecen estos significativos montos un análisis más claro y transparente?

\section{REFERENCIAS BIBLIOGRÁFICAS.}

1. Argañaraz, Capello, Garzón y Grion. ¿Cuál es el verdadero costo de los impuestos? Una revisión de aspectos conceptuales y metodológicos. Documento de discusión $\mathrm{N}^{\text {ro. }} 1 \mathrm{de}$ la Serie Competitividad Fiscal. IERAL de la Fundación Mediterránea, Córdoba Marzo de 2005.

2. Armenteros Diaz M y Vega Falcon V. "Evolución y perspectivas de la Contabilidad de Gestión en Cuba" en Revista Interamericana de Contabilidad de Gestión. Año 1 Nro. 1 Enero-Junio 2003.

3. Asociación Argentina de Presupuesto y Administración Financiera Pública (ASAP). Seminarios de Presupuesto Público 2006-2007. ASAP. Buenos Aires. Agosto de 2008.

4. Atchabahian Adolfo. Régimen jurídico de la gestión y del control en la hacienda pública. Tercera Edición. Buenos Aires: Depalma, 2008.

5. Autores Varios. Trabajos del seminario "Hacia un nuevo sistema tributario". ACARA y Facultad de Ciencias Económicas Universidad Nacional de Buenos Aires. Buenos Aires, 2006.

6. Bértora Héctor. Teoría de la Contabilidad. Buenos Aires. Macchi, 1975.

7. Bird y Casanegra de Jantscher, M. "La Administración Tributaria en los países del CIAT", Instituto de Estudios Fiscales, Madrid, 1992.

8. Bloem A. Recording of taxes in national accounts and government finance statistics. Statistics Department IMF. STD/NA 17. OCDE, 2000.

9. Block Walter. "Comment on McCready and Maloney on wealth taxation http://www. walterblock.com/wp-content/uploads/publications/mccready_maloney.pdf Canadian Public Administration Volume 95. 542-548.

10. Bocardi E. Chapman W. Chyrikins H. Ensayo de un concepto de ganancia realizada. en Revista de Administración de Empresas, T XI, 1974: 289. 
11. Bottaro Oscar. Ganancia Contable. CEA Depart. de Cs. Económicas Universidad Nacional del Sur. Bahía Blanca, 1972.

12. Di Russo Leila y Hauque Sergio. Fundamentos Económicos de la disciplina contable. Cívica. Santa Fe, 2002.

13. Efford D. The case for accrual recording in the IMF's GFS system. IMF Working Paper. Julio de 1996.

14. Evans Chris "The operating costs of taxation: a review of the research" en Institute of Economic Affairs. Blackwell Publishers, Junio de 2001.

15. Filc Gabriel (comp.). "Las políticas fiscales en Argentina: un complejo camino hacia la equidad y la eficiencia”. Buenos Aires. Fundación CIPPEC, 2008.

16. Fondo Monetario Internacional. Revisión del Manual de Balanza de Pagos Quinta Edición. Reseña Comentada. Departamento de Estadística. Abril de 2004

17. Fondo Monetario Internacional. Manual de Estadísticas de Finanzas Públicas. 2001.

18. Fondo Monetario Internacional. Task force on harmonization of Public Sector accounting. Final Report. Marzo de 2006.

19. Fortini Hernando Lattuca Antonio Lopez Santiso Horacio Luppi Hugo Slosse Carlos y Urriza José. Replanteo de la técnica contable. Su estructura básica, su acercamiento a la Economía. Buenos Aires: Macchi, 1980.

20. Fowler Newton Enrique. Cuestiones Contables Fundamentales. Tercera Edición. Buenos Aires: Macchi, 2001.

21. Fundación de Investigaciones Económicas Latinoamericanas. "Crecimiento y equidad en la Argentina. Bases para una política económica para la década. Síntesis y Propuestas” en www.fiel.org.ar Octubre de 2001.

22. Fundación de Investigaciones Económicas Latinoamericanas. La economía oculta en la Argentina. FIEL, Buenos Aires, 2000.

23. Garcia Casella Carlos Luis (director). Elementos para una teoría general de la Contabilidad. La Ley. Buenos Aires: 2001. 
24. Gimenez Carlos M (coordinador). Tratado de contabilidad de costos. Cuarta Edición. Buenos Aires: Macchi, 1987.

25. Harrison A. The background to the 1993 revision of the System of Nacional Accounts. en unstats.un.org/unsd/sna1993/History/backgrd.pdf en Septiembre de 2007.

26. Hauque Sergio "El efecto Olivera Tanzi ante los recursos tributarios devengados" en Anales de las 41as. Jornadas Internacionales de Finanzas Públicas. Córdoba, 2008.

27. Hauque Sergio y Cattaneo Néstor. "Los ingresos tributarios y el principio de lo devengado en la Contabilidad Pública” en Anales del 16to Congreso Nacional de Profesionales en Ciencias Económicas - Rosario - Provincia de Santa Fe, 2006.

28. Hauque Sergio. "El registro de los recursos tributarios del sector publico: campo de prueba para la armonización entre micro y la macrocontabilidad” en Revista del Magister en Administración Pública - Facultad de Ciencias Económicas - Universidad Nacional del Litoral - Nro. 10. 2009.

29. Instituto Nacional de la Estadística y Estudios Económicos (Francia). Time of recording of taxes and social transfers in the French quarterly national accounts en www.insee.fr/en/ indicateur/cnat_trim/Pub_Meth /methodology2004.pdf - Septiembre de 2007.

30. International Federation of Accountants. Transition to the Accrual Basis of Accounting: Guidance for Governments and Government Entities. Study 14. Abril de 2002.

31.International Public Sector Accounting Standard Board. IPSAS Nro. 23. Revenue from non exchange transactions (taxes and transfers). Diciembre de 2006.

32. International Public Sector Accounting Standards Board International Public Sector Accounting Standards and Statistical Bases of Financial Reporting: An analysis of differences and recommendations for convergence Research Report. January 2005.

33. Kesner Skreb Marina “Tax policy and economic growth” en Croatian Economic Survey 1996-1999. Páginas 145-206.

34. Krugman y Wells. Introducción a la economía Microeconomía. Barcelona. Reverte, 2006.

35. Las Heras José María. Estado Eficaz. Buenos Aires. Segunda Edición. Buyatti, 2003. 
36. Las Heras José María. Estado Eficiente. Administración financiera gubernamental Un enfoque sistémico. Buenos Aires: Buyatti, 2004.

37. Llach J. "Un nuevo contrato fiscal federal” en Anales de la XXVI Reunión de la Asociación Argentina de Economía Política. Buenos Aires, 2001.

38. Mallo C, Kaplan R, Meljem S. y Gimenez C. Contabilidad de costos y estratégica de gestión. Madrid: Prentice Hall, 2000.

39. Mansfield Edwin. Microeconomía. Buenos Aires. Grupo Editorial Norma, 1994.

40. Mattessich Richard. Contabilidad y Métodos Analíticos Medición y Proyección del Ingreso y la Riqueza en la Macroeconomía y la Microeconomía. Buenos Aires. La Ley, 2002.

41. Muller Alberto E. G. Economía Descriptiva: Nociones de cuentas nacionales e indicadores socio económicos. Buenos Aires: Catálogos, 1998.

42. Nuñez Miñana Horacio. Finanzas Públicas. Segunda Edición. Macchi. Buenos Aires, 1998.

43. Organización de Estados Americanos. Inflación y Tributación. CIES. Documentos ocasionales. Washington, 1978.

44. Propatto Juan C.A. El Sistema de Cuentas Nacionales Segunda Edición, Buenos Aires. Macchi, 2004.

45. Raimondi C. Ensayo sobre el principio de devengamiento en Revista Administración de Empresas, T XI: 315, 1974.

46. Schumpeter J. Capitalismo, Socialismo y Democracia. Barcelona, Folio, 1996.

47. Schumpeter J. History of Economic Analysis. Oxford University Press, 1968.

48. Smith Adam. Investigación sobre la naturaleza y las causas de la riqueza de las naciones. Fondo Cultura Económica. Segunda Edición en Español. México, 1958.

49. Statistics Denmark. Valuation and time of recording for taxes and social contributions. Paper prepared for the joint UNECE/Eurostat/OECD Meeting of National Accounts Experts, 28-30 April 2004. 
50. Stiglitz J. La Economía del Sector Público. Tercera Edición. Barcelona. Antoni Bosch, 2003.

51. Task Force on Harmonization of Public Sector Accounting. Tax revenues and tax credits. Of the 1993 SNA - Issue No. 35. Issue Paper for the meeting of the AEG. Julio 2005.

52. Villela Lemgruber y Jorrat. Los presupuestos de gastos tributarios. Conceptos y desafíos de implementación. Banco Interamericano de Desarrollo. Sector de Capacidad Institucional y Finanzas. Documento de Trabajo BID IDB-WP 131. Diciembre de 2009.

\section{CURRÍCULUM VITAE} SERGIO MIGUEL HAUQUE.

Doctor en Ciencias Jurídicas y Sociales (Universidad Nacional del Litoral)

Profesor Titular Ordinario de Derecho Empresario (FCE - UNLitoral)

Profesor Titular Ordinario de Introducción a la Economía (FCE - UNEntre Ríos)

Profesor Adjunto Ordinario de Economía de la Empresa (FCE - UNEntre Ríos)

Profesor Adjunto Ordinario de Introducción a la Economía (FCE - UNLitoral)

Profesor Adjunto Ordinario de Microeconomía (FCE - UNLitoral)

Profesor de posgrado en las Universidades de Rosario, Litoral, Nordeste, Río Cuarto, Villa María y Patagonia San Juan Bosco.

Docente Investigador Categoría II

Vicedecano a/c de la Secretaría Académica - Facultad de Ciencias Económicas - Universidad Nacional del Litoral.

sergiohauque@yahoo.com.ar 